\title{
The effect of financial leverage on real and accrual-based earnings management
}

Article

Accepted Version

Anagnostopoulou, S. C. and Tsekrekos, A. E. (2017) The effect of financial leverage on real and accrual-based earnings management. Accounting and Business Research, 47 (2). pp. 191-236. ISSN 2159-4260 doi:

https://doi.org/10.1080/00014788.2016.1204217 Available at https://centaur.reading.ac.uk/65555/

It is advisable to refer to the publisher's version if you intend to cite from the work. See Guidance on citing.

To link to this article DOI: http://dx.doi.org/10.1080/00014788.2016.1204217

Publisher: Routledge

All outputs in CentAUR are protected by Intellectual Property Rights law, including copyright law. Copyright and IPR is retained by the creators or other copyright holders. Terms and conditions for use of this material are defined in the End User Agreement.

\section{www.reading.ac.uk/centaur}

\section{CentAUR}

Central Archive at the University of Reading 
Reading's research outputs online 


\title{
The effect of financial leverage on real and accrual-based earnings management ${ }^{1}$
}

\author{
Seraina C. Anagnostopoulou $*, 2$ \\ Andrianos E. Tsekrekos** \\ *Henley Business School, University of Reading \\ Whiteknights, Reading \\ RG6 6UD, UK. \\ **Department of Accounting \& Finance, \\ School of Business, \\ Athens University of Economics \& Business (AUEB), \\ 76 Patision Str., GR10434, Athens, Greece.
}

\begin{abstract}
Past research has documented a substitution effect between real earnings management (RM) and accrual-based earnings management (AM), depending on relative costs. This study contributes to this research by examining whether levels of (and changes in) financial leverage have an impact on this empirically documented trade-off. We hypothesise that in the presence of high leverage, firms that engage in earnings manipulation tactics will exhibit a preference for RM due to a lower possibilityand subsequent costs - of getting caught. We show that leverage levels and increases positively and significantly affect upward RM, with no significant effect on income-increasing AM, while our findings point towards a complementarity effect between unexpected levels of RM and AM for firms with very high leverage levels and changes. This is interpreted as an indication that high leverage could attract heavy outsider scrutiny, making it necessary for firms to use both forms of earnings management in order to achieve earnings targets. Furthermore, we document that equity investors exhibit a significantly stronger penalising reaction to AM vs. RM, indicating that leverage-induced RM is not as easily detectable by market participants as debt-induced AM, despite the fact that the former could imply deviation from optimal business practices.
\end{abstract}

JEL Classifications: M40, M41

Keywords: leverage, debt, real earnings management, accrual-based earnings management, market performance.

\footnotetext{
$1 \mathrm{We}$ are grateful to the Editor, Professor Edward Lee, and to an anonymous reviewer for helpful comments and suggestions, which greatly improved the paper. We would also like to thank seminar participants at the Essex Business School and the Queen Mary University of London, and to the participants of the American Accounting Association (AAA) 2012 Annual Meeting, held in Washington D.C., USA, and to the participants of the 36th Annual Congress of the European Accounting Association (EAA) 2013, held in Paris, France, for helpful comments and suggestions. Any errors are the authors' sole responsibility.

${ }^{2}$ Corresponding author, Email: seraina.anagnostopoulou @ henley.ac.uk, Tel: +44 (0) 1183785606.
} 


\section{Introduction}

Traditionally, corporate funding, ownership and control do not coincide for most listed firms. This results in capital owners and/or providers not having full decision-making rights when asymmetric information exists between inside and outside parties to the firm. In order to solve this agency problem, implicit and explicit contracts use accounting information relating to the use of resources, or generated return on investments (Beyer at al. 2010), with this information to be judged ex-post (with reference to the point in time in which capital was provided). Capital providers assess the performance of firms through the use of such information (Beyer at al. 2010), which enhances management motivation to artificially inflate performance in order to achieve a more favourable related assessment. This creates the conditions necessary for earnings management to take place in order to achieve managerial goals with respect to securing external funding. Manipulation of reported accounting information through earnings management severely impairs the ability of both potential creditors and investors to correctly assess future firm prospects and the managerial use of committed funds.

There exists a significant amount of research on earnings management (hereafter EM) based on accruals manipulation (accrual-based earnings management, hereafter AM) and/or real transactions (real earnings management, hereafter RM) undertaken in relation to financial leverage (or even change in leverage). A number of studies suggest that firms engage in income-increasing EM (AM or RM) to reduce the possibility of contractual violations (e.g., Defond and Jiambalvo 1994, Sweeney 1994, Jaggi and Lee 2002, or Kim et al. 2011 for RM). However, outside the covenant breach context, other research (e.g., DeFond and Park 1997, Chung et al. 2005, Lee et al. 2007, Perez-Rodriguez and van Hemmen 2010) actually observes a negative association between leverage and signed AM, and the same conclusion is deduced by Jelinek (2007) for leverage increases. This negative association between leverage and upward AM has been attributed to the fact that it may be efficient for creditors to incur the monitoring costs necessary to assess the real quality of debtors. Consequently, debt should be expected to actually limit opportunistic behaviour, in accordance with Jensen's (1986) control hypothesis (Rodríguez-Pérez and van Hemmen 2010).

In relation to the forms that EM can take, past research has considered that RM is harder to track and scrutinise for outside parties, e.g., auditors or regulators, in comparison to AM (Cohen et al. 2008, Cohen and Zarowin 2010, Gunny 2010, Zang 2012). This is because RM can be easily masked in the form of everyday business transactions, while AM involves accounting methods more easy to assess and monitor by outsiders (Roychowdhury 2006). According to the control hypothesis by Jensen (1986), one expects at the same time leverage to be accompanied by increased monitoring and scrutiny on the part of outside creditors. In this study, we expect that this stronger outsider monitoring in relation to leverage should be extrapolated for any outside party with an investment interest in the firm, for example, equity 
investors. We examine whether higher levels of leverage (or increases in leverage) should be expected to induce a preference for RM over AM among firms with an increased motivation to engage in EM in order to meet or beat earnings targets (in order to avoid reporting a loss or a decrease in earnings compared to previous year, or to meet analyst earnings' forecasts), hereafter referred to as suspect firms. This is because on one hand, creditors are interested in assessing and monitoring a firm's risk profile (for estimating probabilities of default or for pricing new debt financing offered to the firm), while on the other, equity investors assess and monitor the same risk profile in their evaluation of firm investment opportunities (by calculating required rates of return).

Firms with high leverage (or significant leverage increases) could be subject to a number of different motivations for engaging in EM in order to affect the perceptions of outside capital providers (debt or equity investors). These include hoping to improve the conditions at which they secure funding (Rodriguez-Perez and van Hemmen 2010), to improve their reserve bargaining power by reducing creditors' perceived risks (Watts and Zimmerman 1986), to avoid debt covenant violations (Defond and Jiambalvo 1994, Sweeney 1994, Jaggi and Lee 2002), to raise additional debt under favourable contracting terms, or to 'maintain rapport with lenders in anticipation of repeat transactions' (Ronen and Yaari 2005). Leverage (or increases in leverage) has been shown to have a negative impact on market performance (see Bradshaw et al. 2006, Cohen and Lys 2006, Penman et al. 2007, Dimitrov and Jain 2008, Gu 2008, Cai and Zhang 2011). Thus, high levels of debt could also prompt the motivation to present an improved picture of the firm for existing and potential shareholders as well, if firms wish to reduce the negative impact that leverage (or increases in leverage) has been shown to have on market performance (Bradshaw et al. 2006, Cohen and Lys 2006, Penman et al. 2007, Dimitrov and Jain 2008, Gu 2008, Cai and Zhang 2011). We expect, then, that if a firm wishes to engage in EM for reasons related to its leverage, it should have a preference for the form of EM which is less open to scrutiny by outside parties, that is, RM, as opposed to the easier to track AM.

Moreover, and in relation to the manifestations that EM can take, according to Zang (2012), $\mathrm{AM}$ and RM are expected to represent a joint, rather than a simultaneous, decision, depending on the relative costs and benefits of each type of EM, with the costs of AM increasing with stronger outsider monitoring (Zang 2012, Roychowdhury 2006). Zang (2012) provides evidence that firms suspected of earnings manipulation tactics can substitute one form of EM with the other, given their sequential (and not simultaneous) nature: in her sample of suspect firms she reports evidence that AM is undertaken posterior to unexpected RM, as RM can be undertaken during the entire fiscal year, while AM can be used for fine-tuning current period earnings after the fiscal year has ended but before reporting financial results, depending on 'how much work' has been done using RM in order to achieve earnings targets (Zang 2012). 
In this study, which investigates the effect of leverage on this empirically documented substitution (trade-off), we therefore base our analysis on the theoretical and empirical conclusions deduced by Zang (2012) to the effect that the decision to engage in AM and RM is a joint rather than a simultaneous one, with the decision determining the levels of AM lagging behind the decision to engage in RM. This would be applicable to all firms suspected of engaging in EM in order to achieve earnings targets.

At the same time, we consider that any motivation for EM with reference to levels of leverage can also apply to changes (increases) in leverage. This is because under asymmetric information between managers and outside parties, we expect, as would be the case for higher vs lower leverage levels, that leverage increases should result in the communication to outside capital providers of a higher risk profile for the firm. This could concern both default as well as investment risk, depending on the type of capital provider each time.

If one believes, as we assume in this paper, that outsiders will increase their monitoring efforts when firm financial leverage is or gets higher, then one should expect that leverage levels/changes would influence the trade-off between RM and AM documented by previous research (Zang 2012). Our expectation is that the well-documented (sequential) substitution of unexpected levels of RM (undertaken during the fiscal year) with AM (used after the fiscal year end but before the reporting of financial results) might turn into complementarity for highly-levered suspect firms; as outsider scrutiny increases with leverage, highly-levered suspect firms may not be able to attain earnings targets by relying only on one type of EM.

Using all non-financial firms from Compustat during 1990-2009, and calculating values of proxies for RM (abnormally low levels of discretionary expenses or evidence of overproduction) and AM (discretionary accruals), we first show, through standard portfolio analysis, that higher levels of leverage positively and significantly associate with higher levels of upward RM. At the same time, higher (rather than lower) levels of leverage are not observed to consistently and significantly associate with higher signed discretionary accruals. This empirical conclusion is deduced for firms with an assumed motivation to engage in EM in order to avoid reporting a loss or a decrease in earnings compared to previous year levels, or avoid missing an earnings target set by financial analysts. Furthermore, we implement a Hausman test (Hausman 1978) which confirms that AM is undertaken sequentially to RM. We continue our analysis by employing an empirical setting similar to that of Zang (2012) and Chan et al. (2015) for EM suspect firms, which considers that the decision to engage in $\mathrm{AM}$ and $\mathrm{RM}$ is a joint one, with AM undertaken depending on levels of unexpected RM incurred during the year, depending on relative costs and benefits of both AM and RM. In this setting, we confirm that financial leverage has a significantly positive effect on RM, but no significant influence on AM, with the former effect stronger for higher levels of leverage. At the same time, our findings indicate the existence of a complementarity effect between 
unexpected levels of RM and AM. This becomes very strong for highly indebted firms. In other words, in the presence of high levels of leverage, the trade-off effect between RM and $\mathrm{AM}$ is observed to turn into a complementarity effect. This is interpreted as an indication that very high leverage attracts heavy outsider scrutiny, making it necessary for firms to use RM in combination with AM to be able to achieve earnings targets. Finally, our findings generally remain qualitatively similar (although significantly weaker) when we repeat our analysis for changes in leverage, in addition to levels of leverage.

Furthermore, we examine the impact of leverage-induced RM and AM on the reactions of investors regarding suspect firms, this impact being assumed to become evident in the course of market appraisal in the case of equity investors. We deem this investigation important because past research has hypothesised that RM is more harmful than AM for future firm performance, as the former form of EM represents a departure from possibly optimal business decisions for the mere purpose of influencing reported income (Graham et al. 2005, Cohen et al. 2008). Thus, we aim at assessing whether investors identify and manage to see through such EM practices, i.e., whether investors incorporate such EM actions into the expectations on which they base their equity holding decisions. Stock market participants are expected to react negatively if they manage to see though EM, as they understand that it creates a biased picture of the firm's future cash flow and earnings generation potential. If RM undertaken in relation to levels or changes in leverage by suspect firms is detected with more difficulty than $\mathrm{AM}$, we expect a stronger (negative) association between AM and changes in leverage and market performance compared to RM, at least in the short run. The focus of our investigation on the consequences of leverage-induced EM is on the investor group whose reaction should be the quickest to respond, that is equity investors. Their reaction and stock market valuations could of course in turn affect debt investor perceptions of relevant firms.

Our findings confirm the above hypotheses when we directly test for the possible impact of leverage-induced AM and RM on the subsequent stock market performance of firms for the 3 to 24 months following portfolio formation. By examining the buy-and-hold abnormal returns of double-sorted portfolios, formed based on the amount of firm AM or RM metrics observed in a given year, and the level of firm leverage (and leverage change) in that year, we demonstrate that on average, for a given level of leverage, there exists a significantly negative association between AM and subsequent stock returns in the 3 to 6 months after portfolio formation. This phenomenon is observed to dissipate within one year. In contrast, firms that employ income-increasing RM tactics, when compared to 'same-leverage' firms that refrain from RM, are found to have indistinguishable stock market performance over the following two years, with all results remaining qualitatively similar when the analysis is repeated for changes in leverage, instead of levels of debt. These findings lead to the conclusion that 
equity investors seem to penalise more heavily and readily accrual-based debt-induced EM, which is interpreted as an indication that AM can be more easily detected than RM.

Overall, our findings are consistent with leverage inducing a preference for RM rather than AM. We have identified up to this point two main groups of capital providers whose perceptions on the risk profile of firms could be significantly affected by EM: creditors and equity investors, both existing and potential. The main difference between the two groups relates to the fact that, in contrast to shareholders, even if investment risks increase, debtholders are not residual claimants; they are by definition more concerned with receiving repayment of their capital and interest, rather than with maximising the value of the firm. Thus, if a highly levered firm engages in RM by deviating from optimal business practices, as long as it has enough cash to repay obligations, such a decision could be possibly indifferent or even optimal for its creditors (in the case, for example, where RM takes the form of a reduction in discretionary expenses), but not necessarily for its shareholders. For the latter, optimal actions would be those maximising the value of the firm from a business perspective, which would not be supported by, for example, cutting down on operating costs useful for sustaining or promoting a firm's competitive advantages. At the same time, agency theory considers the value of distressed firms' equity to work in the form of a call option, from which shareholders cannot benefit if a firm's assets decrease in value. Such a decrease may result from possible retraction in its economic activity or loss of competitive advantages due to RM. That is to say, an alternative interpretation for our findings could be that the positive relationship between debt and RM may instead reflect debt-holders' preference, and thus not constitute a pure EM practice in their eyes, but rather a strategy to transfer value and redistribute risks from debt-holders to equity holders. In this respect, RM in the form of overproduction could also work in the same direction as reduction in discretionary expenses, if one considers that overproduction may require additional debt, which may increase debt holders' value (as a firm's debt suppliers) if risk is ultimately borne by shareholders. Furthermore, in the case where debt is supplied by banks, agency problems in banks themselves (involving their executives and owners) would also support a preference for RM, taking into account that debt supply decisions do involve significant agency costs in firms (also from the point of view of relevant fund providers or banks if they play that role). ${ }^{1}$

The contribution of our study is threefold. First, we show that leverage and changes in leverage are factors with a consistent and significant positive impact on upward RM as opposed to AM. We provide evidence that firms with earnings targets in place tend to prefer RM over AM for higher levels of leverage or increases in the latter. This evidence builds on the literature on motivations for EM depending on the level of outside scrutiny by providing

\footnotetext{
${ }^{1}$ We are grateful to an anonymous reviewer for suggesting this argument regarding agency costs in debt providers (e.g., banks).
} 
evidence that an environment of increased monitoring and scrutiny indeed promotes a preference for RM over AM. Second, our study builds on previous research that explores possible factors that simultaneously determine RM and AM by showing that the substitution effect between unexpected levels of RM and AM shown by past research (Zang 2012) may turn into a complementarity effect at very high levels of leverage. In other words, while generally a substitution effect between AM and RM is to be expected, very high levels of leverage (or relevant increases) may mean that firms cannot achieve earnings targets by relying only on one method of EM, so they have to complement one form with the other. This evidence on complementarity between AM and RM, when one single form of EM appears to be insufficient, is consistent with evidence observed by past research in other settings, for example around SEOs by Cohen and Zarowin (2010).

Finally, it has been established in the literature that high amounts of debt may harm firms by causing underinvestment problems (Myers 1977), i.e., an unwillingness to undertake positive net present value projects given that debt will have to be serviced first. High existing debt can thus constitute a motive for deviation from optimal business decisions. Our findings show that leverage-induced AM is significantly more heavily penalised by stock market participants than relevant RM undertaken in relation to leverage, at least for the first months after engaging in such practices. To this effect, our evidence indicates that, for a given level of leverage, capital providers might not react accordingly to income-increasing RM, but do penalise for AM. In this context, despite the fact that the resulting promotion of RM over AM may have more severe economic consequences, in the form of deviation from optimal business practices, nevertheless stock market participants are observed to under-react, in the short-run at least, to this form of EM which is in theory more difficult to detect (RM). This should be of particular interest and concern to investors, as well as to parties engaging in lending to, or any kind of business transactions with, the firm, to the extent that a firm's market performance is considered to be indicative of its true economic performance.

Recent studies (Walker 2013) have called for awareness of empirical research on earnings management with respect to how this research relates to the revelation principle (Dye 1988, Arya et al. 1998). The revelation principle predicts that managers will not be able to benefit from EM unless a number of perfect market conditions hold (Alhadab et al. 2015, Walker 2013). This then requires the provision of an adequate frame for theoretical predictions and empirical findings with respect to which conditions make EM possible each time. Information differentials between managers and outside parties have been considered to represent a setting which may lead to benefits to managers if they engage in EM (Alhadab et al. 2015). In this case, the existence of high levels of financial leverage (or increases in such) is expected to inherently result in differential levels of information between information-sharing insiders and different groups of outsiders; higher debt may very well result in value transfer and risk 
redistribution from debt-holders to equity holders, while EM may result in different perceptions of such groups of outsiders with regard to firm risk, when managers can influence such perceptions via EM tactics. At the same time, the findings of this study on a complementarity effect between AM and RM in the presence of high leverage constitute evidence of multiple forms of EM coexisting for the population of suspect firms, confirming relevant theoretical predictions made by past research (Walker 2013).

The rest of the study is organised as follows: In Section 2, we review the relevant literature that motivates the research hypotheses tested in this study. Sections 3, 4 and 5 describe the earnings management metrics, present the basic methodology employed by the study, and further present the sample selection process and report descriptive statistics for our sample, respectively. Section 6 reports and discusses our empirical findings, while the concluding Section 7 summarises the research findings of the study.

\section{Literature Review and Hypotheses Development}

With reference to securing external funding, the role of accounting information is expected to be twofold: First, it allows capital providers, i.e., both equity investors and creditors, to evaluate firm investment opportunities (the ex-ante or valuation role of accounting information) and it further allows these providers to monitor the use of their committed capital (the ex-post or stewardship role of accounting information, see Beyer et al. 2010). In the case of existing and potential creditors, accounting information is expected to help them to continuously assess firms' credit risk (and changes in such), while in the case of existing and potential equity investors, accounting information should help them assess firms' risk profiles, which have direct repercussions for their expected returns. According to Jensen's (1986) control hypothesis, leverage has been considered to attract increased monitoring and scrutiny on the part of outside creditors, with this monitoring expected to extrapolate for any outside party with an investment interest in the firm, such as equity investors. This is because higher (as opposed to lower) levels of leverage (or increases in leverage) should result in increased credit risk for the firm and an increased likelihood of non-serviced future debt obligations. This higher risk could be making it cost-efficient for creditors to incur the monitoring costs necessary to assess the real quality of debtors, resulting in increased outside monitoring on the part of creditors (Rodríguez-Pérez and van Hemmen 2010). At the same time, however, it could also be worth the cost for equity investors to monitor the going concern of the firm as residual claimants. In this way, in line with arguments suggested by Jensen (1986), we expect that higher levels of debt (or changes in debt) should be accompanied by increased monitoring from external parties providing funding to the firm.

There also exists a significant amount of research on accrual-based and/or real EM (upward or downward) undertaken in relation to the levels of leverage held by firms. Extensive evidence 
suggests that firms engage in income-increasing EM to reduce the possibility of contractual violations (Defond and Jiambalvo 1994, Sweeney 1994, Jaggi and Lee 2002, Beatty and Weber 2003), which is followed, though, by downward earnings management during debt renegotiations (Mohd Saleh and Admed 2005). This type of behaviour has been considered the result of what is known as the 'debt hypothesis' (Fields et al. 2001), stemming from positive accounting theory, which predicts that managers will choose to avoid covenant violations, as such violations are costly (Watts and Zimmerman 1986, 1990). Still, outside the covenant breach context, other research (e.g., DeFond and Park 1997, Becker et al. 1998, Chung et al. 2005, Lee et al. 2007, Zhong et al. 2007, Perez-Rodriguez and van Hemmen 2010) actually observes a negative association between leverage and signed AM. This negative association between leverage and upward AM has been attributed to the fact that it may be efficient for creditors to incur the monitoring costs necessary to assess the real quality of debtors, so debt should be expected to actually limit opportunistic behaviour (Jensen's (1986) control hypothesis; Rodríguez-Pérez and van Hemmen 2010).

Research on RM undertaken in relation to leverage, however, is more limited: Roychowdhury (2006), for example, demonstrates a positive association between the existence of debt in a firm's balance sheet and upward RM. Bartov (1993) finds that firms sell fixed assets to avoid covenant violations and Trueman and Titman (1988) observe that managers use RM to smooth reported income to decrease the cost of debt. More recently, Kim et al. (2011) show that firms use upward RM to avoid covenant violations.

In relation to the manifestations that EM can take, research initially provided evidence on AM or RM on a context-specific basis (e.g., Cohen et al. 2008, before and after the enactment of SOX, or Cohen and Zarowin 2010, on RM for firms engaging in SEOs). Then Zang (2012) extensively examined the use of both AM and RM tactics using a fairly general setting for all firms likely to have engaged in EM in order to meet or beat earnings targets, the so-called suspect firms. According to Zang (2012), AM and RM are expected to represent a joint rather than a simultaneous decision, depending on relative costs and benefits of each type of EM, with the costs of AM increasing with stronger outsider monitoring (Zang 2012, Roychowdhury 2006). Managers' ability to engage in upward AM in the current period, meanwhile, may also be constrained by accrual management activities in previous periods (Zang 2012). RM is by definition undertaken during the fiscal year, while AM can be used for fine-tuning current period earnings after the fiscal year has ended but before reporting financial results. Higher (lower) RM during the year is then expected to be accompanied by lower (higher) AM, depending on 'how much work' has been done using RM in order to achieve earnings targets (Zang 2012). Zang (2012) confirms the sequential nature of the two forms of EM (i.e., that $\mathrm{AM}$ is undertaken posterior to unexpected $\mathrm{RM}$ ) by performing a relevant Hausman test (Hausman 1978), and provides evidence on a direct substitution 
between $\mathrm{AM}$ and unexpected levels of $\mathrm{RM}$ depending on relative costs and benefits. Similarly, a recent study by Chan et al. (2015) examining the use of both forms of earnings management fully adopts the theoretical and empirical conclusions of Zang (2012) in its design, i.e., the sequential nature of AM with respect to RM and substitution between AM and unexpected levels of RM undertaken during the year.

In relation to this point, past research has considered and observed that RM is harder to track and scrutinise for outside parties, e.g., auditors or regulators, in comparison to AM (Cohen et al. 2008, Cohen and Zarowin 2010, Gunny 2010, Zang 2012). For example, Cohen et al. (2008) offer evidence on firms replacing AM with RM due to greater monitoring after the enactment of Sarbanes-Oxley (hereafter SOX), while Zang (2012), as discussed, finds that firms substitute AM with RM and vice versa depending on relative costs, which are expected to be higher for AM in the case of increased outsider scrutiny. This is because RM can be masked in the form of everyday transactions and may thus be indistinguishable from normal or 'business as usual' operations, despite the fact that relevant actions could have been undertaken merely for the purpose of influencing earnings (Roychowdhury 2006). In contrast, AM only involves modifications in accounting methods and has an impact on accruals, and is thus expected to be relatively easier for outsiders to identify. Consequently, despite the fact that RM involves business decisions and direct cash flow consequences while AM does not (Cohen and Zarowin 2010), it may be preferred to AM because the latter bears a higher risk of direct repercussions involving greater private costs for managers if caught (Roychowdhury 2006).

These outsiders may take the form of regulators (e.g., the SEC, resulting in class action litigation, see Gunny 2010) or auditors (see Roychowdhury 2006 and Zang 2012), but may also include creditors, interested in assessing and monitoring a firm's risk profile, and equity investors, interested in predicting and evaluating firm investment opportunities. Firms with high levels of debt (or large increases in debt) could have a number of different motivations for engaging in EM, in order to affect the perceptions of outside capital providers (debt or equity investors). In this respect, highly levered firms have been expected to engage in upward EM to improve the conditions under which they secure funding (Rodriguez-Perez and van Hemmen 2010), improve their reserve bargaining power by reducing creditors' perceived risks (Watts and Zimmerman 1986), or avoid debt covenant violations (Defond and Jiambalvo 1994, Sweeney 1994, Jaggi and Lee 2002).

However, leverage can be connected with motivation for upward EM, even in the absence of possible covenant violations. Presenting a rosy picture of the firm's 'financial slack' through EM can affect any kind of contractual outcome in relation to servicing current debt or being able to raise additional debt in the future and negotiate relevant contracting terms, or it can 
serve to 'maintain rapport with lenders in anticipation of repeat transactions' (Ronen and Yaari 2005, p. 163). ${ }^{2}$

Furthermore, the level of debt could also prompt the motivation to present to equity investors (existing or potential) an improved picture of the firm, in the case that firms wish to reduce the negative impact which leverage has been shown to have on stock market performance (Bradshaw et al. 2006, Cohen and Lys 2006, Penman et al. 2007, Dimitrov and Jain 2008, Gu 2008, Cai and Zhang 2011). This negative effect of high leverage on subsequent stock market performance has been found to be robust to a number of controls for risk or mis-pricing (Penman et al. 2007) and to contradict theoretical predictions about a positive association between risk and return (Piotroski 2007, Gu 2008). This result, in the case of leverage changes, has been considered by Cai and Zhang (2011) to be consistent with the market penalising for possible underinvestment problems, as underinvestment may reduce future growth opportunities for the firm, in line with the relevant hypothesis by Myers (1977). Were a high-debt firm aware of this negative pricing of leverage by the market, it may want to engage in window-dressing tactics to mitigate this effect of leverage. An unfavourable market pricing is undesirable by firms and their management in many respects, ranging from managers' career concerns and bonuses and their external reputation together with that of the firm - with a corresponding effect on the ability to secure capital and attract investors in the future - to political visibility (Graham et al. 2005).

In this way, based on the assumption that higher levels of leverage (or changes in leverage) are likely to be accompanied by heavier scrutiny by outside parties (auditors, regulators, and also debt and equity investors), combined with the assumption that RM is less easily detectable than AM in accordance with extensive respective arguments and/or evidence provided by past research, we expect that if a firm wishes to engage in EM, it should have a preference for RM in relation to AM, leading to our first research hypothesis:

H1: Other things being equal, higher levels of leverage (or increases in leverage) are expected to induce a preference for RM over AM among suspect firms engaging in EM.

To test the above hypothesis, and for all subsequent arguments and hypotheses, we base our analysis on the theoretical and empirical conclusions deduced by Zang (2012) that the decision to engage in AM and RM is a joint rather than a simultaneous one, with the decision determining the levels of AM lagging the decision to engage in RM. Furthermore, no definitive conclusions can be reached on EM undertaken by firms without simultaneously

\footnotetext{
${ }^{2}$ At this point, it should be mentioned that past research has also associated high leverage and specifically debt covenant violation with downward earnings management, in an effort on the part of firms to achieve better concessions during debt renegotiations (Rodriguez-Perez and van Hemmen 2010, Becker et al. 1998, Mohd and Ahmed 2005). Reference is made to this research in order to provide a complete account of different motivations for EM. However, EM in the course of debt renegotiations is considered to represent a more specialised event context.
} 
addressing both forms of EM (Zang 2012). The sample employed for all empirical analyses focuses on suspect firms or firms marginally meeting or beating earnings targets, in accordance with past research (see Roychowdhury 2006, Cohen et al. 2008, Zang 2012, Chan et al. 2015), and EM decisions undertaken by these firms in relation to their levels or changes in financial leverage.

All previous discussion on motivations for EM has mainly been made with reference to levels of leverage, but is expected to also apply to changes (increases) in leverage. As Gu (2008) points out, a leverage increase is expected either when the firm has generated cash flows lower than anticipated, or when there are profitable growth opportunities in place which require funding. The first motivation is obviously not desirable by lenders, while the second one should be welcomed, as long as the debt raised is invested into positive net present value projects (Gu 2008). Under asymmetric information between managers and outside parties, in either case, we expect that, in line with results for higher vs lower leverage levels, leverage increases result in increased risk for outside providers of capital. In the case of creditors, increases in leverage signify potential increases in credit risk, ceteris paribus, while increases in leverage also manifest a higher risk profile for equity investors. Regarding the perception of changes in leverage by outsiders, Jelinek (2007) argues that increases in leverage should reduce opportunistic behaviour, as managers cannot afford to waste money in the presence of predefined payments that need to be made, so leverage increases should reduce EM. She provides evidence that leverage increases lead to a decrease in accrual-based EM, a finding attributed to a reduction in managers' opportunistic behaviour and an increase in discipline. However, in our case, we take a more comprehensive approach with respect to EM in relation to leverage and examine the joint decision to engage in either RM or AM, on which we hypothesise in favour of a tendency of higher levels of leverage to induce RM vs AM as a preferred choice for firms engaging in EM.

As discussed, past research has provided either context-specific evidence (Cohen et al. 2008 on AM getting substituted by RM after the passage of the Sarbanes-Oxley act) or more general but direct evidence (Zang 2012, for all firms marginally meeting or beating earnings' targets) on a substitution between RM and AM, depending on relative costs and benefits (Zang 2012). At the same time, though, other research has observed the simultaneous use of AM and RM (Cohen and Zarowin 2010); in certain situations, it may not be sufficient for a firm to achieve desired earnings targets by engaging solely in AM (Roychowdhury 2006), so both forms of EM may have to be used in order to achieve such targets. In this respect, in the context of assumed increased monitoring by outsiders in the presence of higher levels of leverage (or changes in leverage), we expect that the level of leverage should influence the trade-off between RM and AM observed by past research in an effort to achieve earnings targets. More specifically, we expect a complementary function of AM undertaken after the 
end of the fiscal year but before the reporting of financial results, with unexpected levels of $\mathrm{RM}$ undertaken during the fiscal year. This is because the former type of EM can be used to supplement the result achieved with RM during the financial year, where increased outsider scrutiny in the presence of higher levels of leverage (or changes in such) may not permit firms to achieve earnings targets by relying only on one type of EM. In this case, other things being equal, higher levels of leverage (or increases in leverage) should affect the trade-off or substitution effect between RM and AM established by past research (Zang 2012) for suspect firms, and the relative use of AM combined with RM in order to achieve earnings targets, leading to our second hypothesis:

H2: Highly indebted firms suspect of managing their earnings are expected to complement RM efforts during the fiscal year with AM choices after the year end (but before the reporting of financial results).

Regarding the possible consequences of $\mathrm{AM}$ and $\mathrm{RM}$, past research has generally hypothesised and found that RM is more harmful than AM for the future performance of firms, as the former type of EM represents a departure from possibly optimal business decisions with the mere purpose of influencing reported income (Graham et al. 2005). Gunny (2010) reports that firms engaging in RM to meet earnings benchmarks actually outperformed firms which had not been involved in RM (and missed such benchmarks). However, Graham et al. (2005) and Cohen et al. (2008) argue that RM is a more costly strategy than AM. In a similar vein, Bhorjaj et al. (2009) shows that RM to meet earnings benchmarks is harmful for stock market performance in the long run, but has some temporary benefits, while Badertscher (2011) provides evidence on the use of RM to sustain overvalued equity. Given that EM in any form is by definition expected to influence accounting-based operating performance measures, it is natural to anticipate that any impact that leverage (or leverage changes) might have on AM and RM should affect the active stance that capital providers (creditors and equity investors) take towards the firm. An investigation of subsequent capital provider reaction that simultaneously accounts for leverage levels and increases and possible leverage-induced AM and RM would allow a direct assessment of whether capital providers identify and manage to see through such EM practices, and if so, whether they price such actions through their willingness to lend to the firm (for debt investors) and the determination of stock returns (for equity investors).

At this point, it is assumed that to the extent that RM takes the form of deviation from possibly optimal operating decisions, with simultaneous direct cash flow consequences, it should be more harmful for the future economic value of the firm than AM, and in line with this, past research has considered RM more costly than AM for shareholders (Cohen et al. 2008). We propose that this consideration is in accordance with previously used arguments that equity investors are residual claimants, and therefore more strongly interested in and 
sensitive to the best possible competitive positioning of the firm from a business perspective compared to debt holders, whose main concern should be capital and interest payback rather than firm value maximisation. This argument by no means rejects the fact that equity and debt investors are also harmed by the practice - without cash-flow consequences - of AM, to the extent that AM prevents them from having a correct economic picture of the firm which would permit unbiased investment and credit decisions. However, a distinction between AM and RM is made based on the fact that the latter form of EM incurs cash flow consequences and operating decisions which can make a firm deviate from optimal business positioning.

Debt investors are not residual claimants and are mainly interested in securing debt payback. Nevertheless, to the extent that they are misled by RM and would have possibly taken different debt-related decisions had RM been absent, they are expected to be harmed by RM as well as equity investors, although to a lesser extent due to weaker interest in firm value maximisation compared to equity investors. Thus, both debt and equity capital providers can be expected to react in a negative and penalising way if they see through EM, as they understand that it creates a biased picture of the firm's credit risk profile and future cash flow and earnings generation potential. In the case of debt investors, relevant reaction could, for example, take the form of refusing to provide additional funds to the firm, or of providing debt under worse terms, while equity investors could react more immediately if they detect EM of any form by becoming bearish with respect to the firm's stock. Consequently, if RM undertaken in relation to levels or changes in leverage is detected with more difficulty than $\mathrm{AM}$, we expect a stronger (negative) association between AM and changes in leverage and market performance, compared to RM. This should hold at least in the short run, as the firm's management tells the market 'what they want to hear', according to Bhojraj et al. (2009), until investors have the time to fully evaluate the possible operating implications of RM. Based on arguments employed by previous research, EM of any form should have a negative effect on suspect firm market valuation, on the assumption that it distorts the presentation of the true financial position of the firm at the risk of getting caught and penalised accordingly. We expect that high leverage should play a role in this valuation, and to the extent that EM results in creating a masked picture of suspect firm value to equity investors, the EM form expected to be more difficult to detect, i.e., RM as opposed to AM, should have a less negative impact on the perceptions of market participants. This leads to our third hypothesis:

H3: RM rather than AM, undertaken in relation to leverage levels, should have a less negative effect on market valuation because of greater difficulties of detection. The same less negative effect should apply to increases in leverage.

It should be mentioned at this point that the focus on equity rather than debt investor reaction is mainly based on the observation that the former group has the possibility of reacting more quickly to any detected RM and AM, through the formation of stock returns. Debt investors, 
however, may react in ways not so readily perceived or understood, or may even react over longer term horizons, by reducing, for example, the amount of debt offered to the firm, or by tightening credit terms, or through deterioration in credit ratings. Thus, we focus on the interest group whose reaction is the most quick to be captured, that is equity investors. Their reaction and stock market valuations could in turn affect debt holders' perceptions of relevant firms. At the same time, we do not assess the consequences of leverage-induced AM and RM in terms of future operating performance measured through the use of accounting figures, as we expect a significant amount of endogeneity to exist in such a process, i.e., assessing the result of a process (EM) which by definition aims at improving reported performance. The formation of stock returns, however, is by construction more immune to influences from reported accounting figures (earnings, but also cash flows, as RM does have cash flow consequences), as it is heavily based on the formation of expectations.

\section{Estimation of Earnings Management Metrics}

3.1 Detecting Accrual-based Earnings Management (AM)

Following previous literature on the joint examination of AM and RM (Roychowdhury 2006, Cohen et al. 2008, Cohen and Zarowin 2010), we test for the existence of AM by estimating discretionary accruals (hereafter DA), i.e., accruals arising from accounting treatments chosen in order to manage earnings. We differentiate these from non-discretionary accruals, or accruals arising from transactions characterised as normal when taking into account a firm's performance, strategy, industry conventions, macro-economic events or other factors (Ronen and Yaari 2005). Previous research simultaneously testing for the existence of AM and RM has mainly made use of unsigned discretionary accruals - rather than signed ones - or has explicitly differentiated between positive and negative ones. However, our hypotheses on the existence of AM and RM depending on the level of leverage are directional in nature. Larcker and Richardson (2004) and Rodríguez-Pérez and van Hemmen (2010) argue than when EM is directional, then the appropriate measure to use for AM is signed or raw accruals, so we make use of signed discretionary accruals, estimated according to the following three methods:

AM Model 1: Modified Jones Model (Dechow et al. 1995)

We first estimate cross-sectionally the following regression for all years according to 2-digit SIC codes:

$$
T A_{i, t}=\alpha_{0}+\alpha_{1}\left(\Delta \operatorname{Rev}_{i, t}-\Delta A R_{i, t}\right)+\alpha_{2} P P E_{i, t}+e_{i, t}
$$

where (Compustat item \# in parentheses):

$T A_{i, t}=$ firm $i$ 's Total Accruals calculated from the Cash Flow Statement 
(TACFS) in year $t$, defined as $\left(N I B E_{i, t}-C F O_{i, t}\right)$;

\begin{tabular}{|c|c|c|}
\hline$N I B E_{i, t}$ & $=$ & firm $i$ 's Net Income Before Extraordinary items (\#123) in year $t$; \\
\hline$C F O_{i, t}$ & $=$ & firm $i$ 's Cash Flows from Operations (\#308) in year $t$; \\
\hline$\Delta R e v_{i, t}$ & $=$ & firm i's change in Revenues (\#12) between year $t-1$ and year $t$; \\
\hline$\Delta A R_{i, t}$ & $=$ & $\begin{array}{l}\text { firm } i \text { 's change in Accounts Receivable (\#2) between year } t-1 \text { and } \\
\text { year } t \text {. }\end{array}$ \\
\hline$P P E_{i, t}$ & $=$ & firm $i$ 's gross value of Property, Plant and Equipment (\#7) in year $t$; \\
\hline$e_{i, t}$ & $=$ & error term. \\
\hline
\end{tabular}

All regression variables in the above equation (including the constant term) are scaled by Total Assets (\#6) at the end of year $t-1$. $^{3}$

We then use the industry and year-specific parameter estimates $\hat{\alpha}_{0}, \hat{\alpha}_{1}$ and $\hat{\alpha}_{2}$ to infer discretionary accruals via:

$$
D A M J_{i, t}=T A_{i, t}-\hat{\alpha}_{0}-\hat{\alpha}_{1}\left(\Delta R e v_{i, t}-\Delta A R_{i, t}\right)-\hat{\alpha}_{2} P P E_{i, t}
$$

We will denote discretionary accruals estimated from the Modified Jones model with $D A M J_{i, t}$. In estimating this model, we subtract the change in accounts receivable from change in revenues before model estimation, following Kothari et al. (2005), DeFond and Park (1997) or Cohen et al. (2008).

For robustness purposes, we make use of two alternative estimation methods for DA, results on which are reported in some instances and mentioned among robustness checks in others.

AM Model 2: Jones Model (Jones 1991)

We first estimate cross-sectionally the following regression for all years according to 2-digit SIC codes:

$$
T A_{i, t}=\beta_{0}+\beta_{1} \Delta R e v_{i, t}+\beta_{2} P P E_{i, t}+\varepsilon_{i, t},
$$

where all variables as before. Then we use the industry and year-specific parameter estimates $\hat{\beta}_{0}, \hat{\beta}_{1}$ and $\hat{\beta}_{2}$ to infer firm-specific discretionary accruals from the Jones model $\left(D A J_{i, t}\right)$ through

$$
D A J_{i, t}=T A_{i, t}-\hat{\beta}_{0}-\hat{\beta}_{1} \Delta \operatorname{Rev}_{i, t}-\hat{\beta}_{2} P P E_{i, t}
$$

AM Model 3: ROA-Adjusted Model (Kothari et al. 2005)

\footnotetext{
${ }^{3}$ As our models for the examination of AM (and RM that follows) are estimated according to year and industry, we require a minimum of 8 observations for every 2-digit SIC code in every year (Cohen et al. 2008, Cohen and Zarowin 2010).
} 
We first estimate cross-sectionally the following regression for all years according to 2-digit SIC codes:

$$
T A_{i, t}=\gamma_{0}+\gamma_{1}\left(\Delta R e v_{i, t}-\Delta A R_{i, t}\right)+\gamma_{2} P P E_{i, t}+\gamma_{3} R O A_{i, t}+\epsilon_{i, t}
$$

where

$R O A_{i, t}=$ firm $i$ 's Return on Assets, calculated as $R_{0} A_{i, t} /$ Assets $_{i, t-1}$, and all other variables as before.

We then use the industry and year-specific parameter estimates $\hat{\gamma}_{0}, \hat{\gamma}_{1}, \hat{\gamma}_{2}$ and $\hat{\gamma}_{3}$ to calculate discretionary accruals $\left(D A K_{i, t}\right)$ by the Kothari et al. (2005) model via

$$
D A K_{i, t}=T A_{i, t}-\hat{\gamma}_{0}-\hat{\gamma}_{1}\left(\Delta R e v_{i, t}-\Delta A R_{i, t}\right)-\hat{\gamma}_{2} P P E_{i, t}-\hat{\gamma}_{3} R O A_{i, t}
$$

For future reference, we define $A M_{i, t}=\left\{D A M J_{i, t}, D A J_{i, t}, D A K_{i, t}\right\}$ as the set of discretionary accruals, estimated by the three models that are employed for the detection of accrual-based earnings management.

We apply all three methods in order to assess the statistical significance of discretionary accruals, and where not reported, relevant results have been calculated as robustness checks. It should be noted that calculating the performance-adjusted discretionary accruals through the use of ROA-matched portfolios as in Zhao and Chen (2008) makes very little qualitative difference to the results.

\subsection{Detecting Real Earnings Management (RM)}

To test for the existence of RM, following previous research (Roychowdhury 2006, Cohen et al. 2008, Cohen and Zarowin 2010), we examine whether firms reduce discretionary expenses or overproduce in order to affect earnings. Specifically, we examine whether firms have abnormally low discretionary expenses, and abnormally high production costs, where both tactics - overproduction and cutting discretionary costs - will have a positive effect on earnings. At this point, past research has also examined whether firms engage in sales manipulation (artificial sales increases) as an EM tactic, which should result in abnormally low cash flows from operations (CFO) (Roychowdhury 2006, Cohen et al. 2008, Cohen and Zarowin 2010). However, overproduction and artificial sales increases will have a negative effect on CFO, while reductions in discretionary expenses will have a positive and thus conflicting influence on CFO (Roychowdhury 2006). This is the reason, for example, that Zang (2012) does not explicitly employ abnormal CFO as a proxy for RM, and we follow her approach to avoid this conflicting result. On this point, Nwaeze et al. (2006) argue that debt might induce firms to manipulate $\mathrm{CFO}$, and levered firms emphasise operating cash flows as a 
performance measure or a device to relax financial constraints, given that creditors may set cash flow rather than profit goals for the issue of new debt. However, despite the fact that CFO creation ability could be a variable of interest for existing and potential debt holders, to avoid the interpretative problems observed for sales manipulation as a RM tactic, we only assess overproduction and reduction in discretionary expenses as RM tactics.

Overproduction: We first express normal cost of goods sold (COGS) as a function of contemporaneous change in sales and estimate cross-sectionally the following regression for all years according to 2-digit SIC codes:

$$
\operatorname{COGS}_{i, t}=a_{0}+a_{1} \operatorname{Rev}_{i, t}+u_{i, t},
$$

where

$\operatorname{COGS}_{i, t}=$ firm $i$ 's Cost of Goods Sold (\#44) in year $t$, and all other variables as before.

We then express normal inventory growth as a function of contemporaneous and past change in sales and estimate cross-sectionally the following regression for all years according to 2digit SIC codes:

$$
\Delta I N V_{i, t}=d_{0}+d_{1} \Delta R e v_{i, t}+d_{2} \Delta R e v_{i, t-1}+v_{i, t}
$$

where

$\Delta I N V_{i, t}=$ firm $i$ 's change in Inventory (\#3) between year $t-1$ and year $t$.

Production costs, $P R O D_{i, t}$, are defined as the sum $C O G S_{i, t}+\triangle I N V_{i, t}$, and normal production costs are defined using the following equation:

$$
P R O D_{i, t}=b_{0}+b_{1} \operatorname{Rev}_{i, t}+b_{2} \Delta \operatorname{Rev}_{i, t}+b_{3} \Delta \operatorname{Rev}_{i, t-1}+\omega_{i, t}
$$

We then use the industry- and year-specific parameter estimates $\hat{b}_{0}, \hat{b}_{1}, \hat{b}_{2}$ and $\hat{b}_{3}$ to infer abnormal production costs $\left(A_{-} P R O D_{i, t}\right)$ :

$$
A_{-} P R O D_{i, t}=P R O D_{i, t}-\hat{b}_{0}-\hat{b}_{1} \operatorname{Rev}_{i, t}-\hat{b}_{2} \Delta R e v_{i, t}-\hat{b}_{3} \Delta R e v_{i, t-1}
$$

Discretionary Expenses: We first express normal discretionary expenses as a function of past sales and estimate cross-sectionally the following regression for all years according to 2-digit SIC codes:

$$
\operatorname{DISEXP} P_{i, t}=c_{0}+c_{1} \operatorname{Rev}_{i, t-1}+n_{i, t}
$$

where 
DISEXP $P_{i, t}=$ the sum of firm $i$ 's R\&D (\#46), Advertising expenses (\#45) and Selling,

General and Administrative Expenses (SG\&A) (\#189) in year $t$,

and all other variables as before.

We then use the industry- and year-specific parameter estimates $\hat{c}_{0}$ and $\hat{c}_{1}$ to infer abnormal discretionary expenses costs $\left(A_{-} D I S E X P_{i, t}\right)$ :

$$
A_{-} D I S E X P_{i, t}=\operatorname{DISEXP} P_{i, t}-\hat{c}_{0}-\hat{c}_{1} \operatorname{Rev}_{i, t-1}
$$

All regression variables in the above equations for RM detection (including the constant terms) are scaled by Total Assets (\#6) at the end of year. Cross-sectional regression estimation for capturing accruals-based (e.g., DeFond and Jiambalvo 1994) or real earnings management (Roychowdhury 2006, Cohen et al. 2008, Cohen and Zarowin 2010, Gunny 2010) follows directly from the literature.

In addition, given that our hypotheses are focused on positive or upward EM depending on firm leverage, we additionally include one comprehensive measure for RM in our analysis, which combines the use of both RM tactics described above (discretionary expense manipulation and overproduction). Following the exact computational procedure of Cohen and Zarowin (2010), to calculate this measure, denoted RM1, we multiply abnormal discretionary expenses by minus one (so that the higher the amount, the greater the possibility that the firm is cutting discretionary expenses), and we add this to abnormal production costs. The multiplication of abnormal discretionary expenses by minus one also applies to all results subsequently reported for this RM proxy on a stand-alone basis. Thus, the higher the value of RM1, the more likely it is that the firm is engaging in positive RM. We define here, for future reference, the set of real earnings management metrics $R M_{i, t}=\left\{A_{-} P R O D_{i, t}, A_{-} D I S E X P_{i, t}, R M 1_{i, t}\right\}$ for all firm-years.

\section{Research Approach and Methodology}

\subsection{Earnings Management by Suspect Firms and Potential Sample Bias}

Since the focus of this study is to investigate the effect of leverage on the empirically documented trade-off between the two earnings management approaches (AM and RM), our hypotheses in Section 2 are tested on a sample of firms where earnings management is likely to take place. As in previous research, it is expected that using a sample of firms that are suspected of implementing earnings management "increases the power of the tests of the trade-off decisions" (Zang 2012, p. 683).

In accordance with the definitions and methodology employed by past research (Roychowdhury 2006, Cohen et al 2008, and mostly Zang 2012), we start with the population 
of firms in Compustat between 1990 and 2009 (excluding firms from regulated industries, i.e., SIC codes between 4400-5000, and financials, SICs in 6000s) and consider suspect firms to be the ones falling into one of the following categories:

(a) firms beating or meeting the zero-earnings benchmark, i.e., firm-year observations with earnings before extraordinary items over lagged total assets (Compustat items \#18/lagged \#6) between 0 and $0.5 \%$,

(b) firms just beating/meeting previous-year earnings, i.e., firm-year observations with a change in basic EPS excluding extraordinary items (change in Compustat item EPSPX) from previous year between 0 and 2 cents, and

(c) firms just beating/meeting analysts' consensus forecasts, i.e., firm-year observations with actual EPS minus the last analysts' consensus forecast provided in the I/B/E/S Database between 0 and 1 cent.

Without imposing any other sample selection criteria until this point, the above criteria yield a total of 9,855 suspect firm-year observations during 1990-2009. ${ }^{4}$

Focusing our hypotheses testing on the (non-randomly selected) sample of EM suspect firmyears that satisfy one of the above three criteria creates a potential omitted-variable problem, since the coefficients of any regression model estimated on such a non-randomly selected firm-year sample could be biased. ${ }^{5}$ As is standard in the treatment of such violations of the exogeneity requirement due to possibly omitted variables, we employ the Heckman (1979) two-step procedure to correct for the potential sample selection bias. In the first step of the procedure, known as the 'selection equation', the following probit model is estimated:

$$
\begin{gathered}
\operatorname{Pr}\left[\text { SUSPECT }_{i, t}=1\right]=\Phi\left(\mathbf{z}_{i, t} \boldsymbol{\gamma}+e_{i, t}\right)=\Phi\left(\gamma_{0}+\gamma_{1} \text { HabBeat }_{i, t}+\gamma_{2} \text { AnalystFollow }_{i, t}\right. \\
\left.+\gamma_{3} \text { Shares }_{i, t}+\gamma_{4} \text { MtoB }_{i, t-1}+\gamma_{5} \text { ROA }_{i, t}+\sum_{k} \gamma_{6, k} \text { YearIndicator }_{k, i, t}+e_{i, t}\right)
\end{gathered}
$$

In the above, the dependent variable, $S U S P E C T_{i, t}$, is a dummy variable that equals 1 if firm $i$ in year $t$ is suspect of earnings management (fulfils one of the criteria a-c above), and zero for non-suspect firm-years (see below for their definition). $\Phi($.$) denotes the cumulative$

\footnotetext{
${ }^{4}$ In the sections that follow, the actual (usable) number of suspect firm-year observations decreases, as we further require that (a) at least one of our $A M_{i, t}$ and $R M_{i, t}$ metrics (outlined in sections 3.1-3.2) can be computed for at least one year for each suspect firm, and (b) data for a number of control variables are available for our suspect firm-years. Section 5 provides a complete description of the sample selection procedure and detailed descriptive statistics.

${ }^{5}$ As Vella (1998) points out, the omitted variables bias is probably the most commonly encountered problem in social and behavioural sciences, with self-selection one of the main common sources of this bias (see Wooldridge 2002).
} 
distribution function of the standard normal distribution, $\gamma$ is the vector of coefficients and $\mathbf{z}_{i, t}$ is the vector of independent variables of firm $i$ in year $t$.

Equation (1) is estimated on the union of two samples: the sample of suspect firm-years (see criteria a-c above) and a sample of non-suspect firm-years that is defined as in Zang (2012). Non-suspect firm-years are considered to be the ones falling into one of the following categories:

(a) firms missing or beating the zero earnings benchmark by 2.5 percent of lagged total assets (Compustat item \#18/lagged \#6) or more,

(b) firms missing or beating previous year EPS (change in Compustat item EPSPX) by more than 5 cents, and

(c) firms missing or beating analyst's consensus forecasts by more than 5 cents.

Again, from the population of firms in Compustat between 1990 and 2009 (excluding firms from regulated industries and financials and without imposing any other data availability criteria until this point), there are 85,305 non-suspect firm-year observations.

The choice of independent variables in equation (1) follows prior research on the factors which could potentially affect the incentive to beat or meet earnings targets. ${ }^{6}$ Specifically,

HabBeat $_{i, t}=$ the number of times (with reference to the end of year $t$ ) that firm $i$ has beaten or met the analysts' consensus forecast (from $\mathrm{I} / \mathrm{B} / \mathrm{E} / \mathrm{S}$ ) in the past four quarters;

AnalystFollow $_{i, t}=$ the $\log$ of 1 plus the number of analysts following firm $i$ as of the end of year $t$;

Shares $_{i, t} \quad=\quad$ the log of the number of shares outstanding (\#25) for firm $i$ at end of year $t$;

$M t o B_{i, t-1}=$ the market-to-book ratio of firm $i$ at the beginning of year $t$, used as a proxy for firms' growth opportunities. Market value is calculated by multiplying the closing price at fiscal year-end by the number shares outstanding, ((\#199*\#25)/\#60);

$R O A_{i, t}=$ is a proxy for firm profitability (Return on Assets), defined as income before extraordinary items, scaled by total assets (\#18/\#6) of firm $i$ in year $t$.

(Compustat item \# in parentheses where appropriate).

\footnotetext{
${ }^{6}$ For detailed analysis and justification for the inclusion of these variables in the first step of the Heckman (1979) approach, see Zang (2012), Chan et al. (2015) and the references therein.
} 
The estimation of the selection equation (1) on the union of suspect and non-suspect firmyears provides the non-selection hazard (what Heckman, 1979, referred to as the inverse Mill's ratio, $I M R_{i, t}$ ) that augments our main regression equations to correct for potential selection bias. ${ }^{7,8}$

4.2 The Effect of Leverage on the Trade-off between Real Earnings Management and Accrual-Based Earnings Management

In order to test our hypotheses on the effect of leverage on the trade-off between RM and AM, we estimate the following recursive system of equations using the earnings management suspect firm-year sample:

$$
\begin{aligned}
R M_{i, t}= & \alpha_{0}+\alpha_{1} \text { Lev }_{i, t}+\sum_{k} \alpha_{2, k} \text { Costs of } R M_{k, i, t}+\sum_{l} \alpha_{3, l}{\text { Costs of } A M_{l, i, t}} \\
& +\sum_{m} \alpha_{4, m} \text { Controls }_{m, i, t}+\varepsilon_{i, t} \\
A M_{i, t}= & \beta_{0}+\beta_{1} \text { Lev }_{i, t}+\sum_{k} \beta_{2, k} \text { Costs of } R M_{k, i, t}+\sum_{l} \beta_{3, l}{\text { Costs of } A M_{l, i, t}} \\
& +\sum_{m} \beta_{4, m} \text { Controls }_{m, i, t}+\beta_{5} \text { UnexpectedRM }_{i, t}+\beta_{6}\left(\text { UnexpectedRM }_{i, t} \times \text { Lev }_{i, t}\right)+\epsilon_{i, t}
\end{aligned}
$$

The research approach follows directly from similar empirical investigations on the trade-off between different earnings management tactics (see Zang 2012) and the potential economic effect of variables on this trade-off (e.g., Chan et al. 2015, for clawback provisions, etc.). The measures of real activities manipulation $R M_{i, t}=\left\{A_{-} P R O D_{i, t}, A_{-} D I S E X P_{i, t}, R M 1_{i, t}\right\}$ are

\footnotetext{
${ }^{7}$ Let $\Phi\left(\mathbf{z}_{i, t} \widehat{\boldsymbol{\gamma}}\right)$ denote the estimates from the probit selection equation (1). Then the inverse Mill's ratio $I M R_{i, t}$ is estimated as $\varphi\left(\mathbf{z}_{i, t} \widehat{\gamma}\right) / \Phi\left(\mathbf{z}_{i, t} \widehat{\gamma}\right)$ for each suspect firm and is included in the second step equation of the Heckman (1979) procedure. $\varphi($.$) is the density of the standard normal distribution.$

${ }^{8}$ Our sample period begins in 1990 rather than in 1987 as in Zang (2012) and Roychowdjury (2006) because of data availability issues. In relation to how the numbers of observations for suspect firms reported by our study compare to relevant numbers reported by previous studies making use of approximately the same data set, our numbers are in line and closer to the ones reported by Roychowdjury (2006) rather than Zang (2012), when taking into account the sample period used by the respective studies. At the same time, all variables included in our analyses performed have been truncated at $1-99 \%$ on a variable-by-variable and year-by-year, while other studies make use of winsorising at 1-99\% (Zang 2012, p. 689). Regarding numbers of observations reported for suspect firms by past research, in more detail, altogether, Roychowdhury (2006) identifies 503 suspect firmyears during 1987-2001 by defining suspect firm years where they have Net Income/Total Assets $>=0$ but $<0.005$, while Zang (2012), according to her first suspect-firm definition, defines suspects as firms just beating/meeting the zero benchmark, or firm-years with earnings before extraordinary items over lagged total assets between 0 and 0.5 percent, and finds 3,428 such firm-year observations (see Zang 2012, p. 690 Table 2, Panel A, and also Table description) for a sample period extending from 1987 to 2008. We make use of three (out of Zang's four) definitions of 'Suspect' firm-years. Finally, our study follows a different approach when defining the 'Suspect' firm dependent variable in the probit model of Equation (1) in the first step of the Heckman procedure: Equation (1) is estimated on the union of two samples: the sample of suspect firm-years and a sample of non-suspect firm-years that is defined as in Zang (2012), while Zang (2012) reports that 'The dependent variable in the selection model is Suspect, which equals 1 if a firm just beats/meets one of the earnings benchmarks discussed above, and 0 otherwise.' (Zang 2012, p.684).
} 
expected to be negatively associated with their respective costs and positively affected by the costs associated with accrual-based earnings management (and vice-versa for $A M_{i, t}=$ $\left.\left\{D A M J_{i, t}, D A J_{i, t}, D A K_{i, t}\right\}\right)$.

The system of equations above is recursive, in that the decisions of suspect firms to engage in $\mathrm{AM}$ and RM are sequential (and not simultaneous); real activities manipulation is executed and realised during the fiscal year, with accrual-based earnings management serving 'finetuning' purposes based on the observed impact of RM after the year-end but before the release of financial statements. The substitutive relationship between real activities manipulation and accrual-based earnings management established by previous research predicts a negative sign for $\beta_{5}$ in the $A M_{i, t}$ equation of the system. ${ }^{9}$

Our coefficients of interest in the above system (that follows largely from previous research) are $\alpha_{1}, \beta_{1}$ and $\beta_{6}$. Our hypothesis $H 1$, that higher leverage (the $L e v_{i, t}$ variable in the equations) and the stronger scrutiny by outside parties (auditors, regulators, and also debt and equity investors) which accompanies it makes firms prefer RM tactics (that are more difficult to detect) to AM, predicts a positive $\alpha_{1}$ and a non-positive $\beta_{1}$ after controlling for the costs of managing earnings and other variables. Moreover, if leverage affects the substitutive relationship between $\mathrm{AM}$ and $\mathrm{RM}$ (our hypothesis $H 2$ ), then $\beta_{6}$, the coefficient of the interaction term UnexpectedR $M_{i, t} \times \operatorname{Lev}_{i, t}$, should be significant, even after controlling for the individual effects of UnexpectedRM $M_{i, t}$ and $L e v_{i, t}$. In addition, if our hypothesis $H 2$ is true, that highly indebted firms suspected of managing their earnings might actually complement RM efforts with AM choices after the fiscal year-end, then the coefficient $\beta_{6}$ should be positive and significant.

The variables used as proxies for the costs associated with RM and AM are based on Zang (2012); they are also employed as cost proxies by other studies on the topic (see Chan et al. 2015). Costs associated with real earnings management are proxied by variables Costs of $R M_{k, i, t}=\left\{\right.$ MarketShare $_{i, t-1}, Z$ ZCore $\left._{i, t-1}, M T R_{i, t}\right\}$. As firms that enjoy market leadership in an industry might perceive RM tactics as less threatening (costly) for their competitive advantage, we expect a suspect firm's market share in its industry to be inversely related to its employment of RM tactics. We use MarketShare M $_{-1}$, at the beginning of year $t$, measured as the ratio of a company's sales to the total sales of its industry (using three-digit SIC codes for industry definition) to capture this. Altman's Z score (Altman 1968) at the beginning of year $t$, denoted $Z S$ core $_{t-1}$, is also included as a cost proxy for RM. As in Zang

\footnotetext{
${ }^{9}$ Our maintained hypothesis that the decisions of suspect firms to engage in AM and RM are sequential in nature is confirmed by the results of a Hausman test (Hausman, 1978) we conduct for the endogeneity of $R M_{i, t}$ and $A M_{i, t}$. To conserve space, we make the details and results of the test available upon request.
} 
(2012), a firms' financial health is expected to affect its use of RM tactics, with higher values of this score being indicative of stronger financial health, and thus lower costs associated with RM. ${ }^{10}$ Finally, we use a firm's marginal tax rate at the end of the year, denoted $M T R_{t}$, as a proxy for costs related to RM, with higher values for $M T R_{t}$ indicating higher costs of real earnings management. ${ }^{11}$

With respect to costs associated with $\mathrm{AM}$ activities, we use $B I G_{t}$, a dummy variable equal to one if the auditor for firm $i$ in year $t$ is one of the Big 4 auditing firms, and zero otherwise. This variable is expected to represent a proxy for the scrutiny of auditors and regulators, with higher scrutiny increasing the cost of engaging in AM activities. Moreover, as in previous research, we employ two variables that are expected to proxy for a firm's flexibility within accounting systems. These variables are $N O A_{t-1}$, or Net operating assets at the beginning of the fiscal year, and $C_{y c l} e_{t-1}$, or a firm's operating cycle at the beginning of the year. $N O A_{t-1}$ is a binary variable equal to 1 if net operating assets (stockholders' equity minus cash and marketable securities plus total debt at the beginning of the year divided by lagged sales, or $(\# 216-\# 1+(\# 34+\# 9)) /($ lagged \#12) in Compustat items) are above the industry-year median (using 2-digit SIC codes for industry definition), and 0 otherwise. The operating cycle at the beginning of the year, $C y c l e_{t-1}$, is computed as the number of days receivable plus the days inventory less the days payable at the beginning of the year (Net Trade Cycle Compustat item TRCYCLE). AM costs are expected to increase with overstated beginning-of-year NOA, as such an overstatement would limit the potential for AM during the current fiscal year. At the same time, a longer operating cycle would increase the potential for AM, in the presence of longer accounts and thus longer periods for accrual reversal (Zang 2012).

Control variables included in (2) again follow from past research (Roychowdhury 2006; Zang 2012; Chan et al. 2015). We include $M t o B_{t}$ to proxy for a firm's growth (variable computed as previously defined in Section 4.1). Imposing a control for growth is justified by the observation that firms with high growth may have a greater reluctance to report losses, while such firms may also have higher accruals than one would expect, compared to firms with lower than expected growth (McNichols 2000). We also employ proxies for profitability $\left(R O A_{t}\right.$, as defined in Section 4.1) and firm size $\left(\right.$ Assets $\left._{t}\right)$, with the latter calculated as the log

\footnotetext{
${ }^{10}$ We follow the approach by Graham et al. (2008) for ZScore calculation and do not include the ratio of market value of equity to book value of total debt, since a similar term, market-to-book, enters the system in (2) as a separate variable. ZScore is calculated following Graham et al. (2008) as: $(1.2 *$ working capital $+1.4 *$ retained earnings $+3.3 * \quad$ EBIT $+0.999 *$ sales $) /$ total assets, or $\left(1.2^{*} \# 179+1.4^{*} \# 36+3.3^{*} \# 170+0.999^{*} \# 12\right) / \# 6$. However, when Altman's (1968) Z Score is employed out of the regression estimation context (e.g., with respect to definitions of distressed firms using cut off points in subsequent analyses), this term is included for the estimation of the Score, and in these cases the Score is denoted as 'Altman's $Z$ '.

${ }^{11}$ We would like to thank Professor John Graham (Graham and Mills 2008, Graham 1996a, 1996b, http://faculty.fuqua.duke.edu/ jgraham/) for providing us with the data on MTR.
} 
of total assets at the end of the fiscal year (log of \#6). Such controls have been shown to significantly affect EM (in the case of RM, for example, see Roychowdhury, 2006, or Cohen et al., 2008). Finally, we follow Roychowdhury (2006) and include a proxy for inventories and receivables (INVRECT $A_{i, t}$, defined as the sum of inventories and receivables, scaled by total assets $((\# 3+\# 2) / \# 6)$ of firm $i$ in year $t)$ in the RM regression, since firms with large inventories and receivables may have greater flexibility to engage in RM (Roychowdhury 2006).

In the system (2), leverage $\operatorname{Lev}_{i, t}$ is defined following Roychowdhury (2006) and Dimitrov and Jain (2008) as the sum of short- and long-term debt, scaled by total assets, ((\#34+\#9)/ (\#6)). Change in leverage, $\Delta L e v_{i, t}$, when it appears in our empirical investigation later on, is defined as the difference between the end-of-year and the beginning-of-year values for $L e v_{i, t}$, following Dimitrov and Jain (2008). As in Zang (2012), in the accrual-based earnings management equation, Unexpected $R M_{i, t}$ is measured as the residuals from the real earnings management equation, and the Heckman system of equations is estimated recursively, first equation (1) with the real earnings management equation as the Heckman second stage, and then equation (1) with the accrual-based earnings management equation.

\section{Sample Selection and Descriptive Statistics}

We make use of all firms from Compustat between 1990 and 2009, excluding firms from regulated industries (SIC codes between 4400-5000) and financials (SICs in 6000s). By applying our definitions of suspect and non-suspect firm-years (see Section 4.1) we identify 9,855 suspect and 85,305 non-suspect potential firm-year observations. The number of firmyear observations from this point onwards becomes data and test specific as we further require that firms have data available for the calculation of at least one of our AM and RM metrics and for the control variables defined in the previous section.

Table 1 reports descriptive statistics (mean, median $25^{\text {th }}$ and $75^{\text {th }}$ percentile values and standard deviation) for our sample suspect firm-years over 1990-2009. All variables are as defined in the previous sections and are truncated at percentiles $1 \%$ and $99 \%$ to mitigate the possibility of extreme observations distorting our results. ${ }^{12}$ For comparability purposes with other RM measures, the proxy for abnormal discretionary expenses (A_DISEXP) has been multiplied by minus one, so that the higher the value of this variable, the greater the possibility of a firm engaging in upward RM.

Insert Table 1 here.

\footnotetext{
${ }^{12} \operatorname{Lev}_{i, t}$ is actually truncated at $1 \%$ and $98 \%$ to eliminate a few observations (about twenty) with a leverage ratio in excess of 10 .
} 
Descriptive statistics, for leverage medians, generally confirm the values obtained by previous studies in the field (Roychowdhury 2006, Cohen et al. 2008): the median leverage ratio is $21.75 \%$, close to median values obtained, for example, for a less restricted sample by Cohen et al. (2008). Our sample suspect firms further exhibit a median operating cycle of about 74 days, and the sum of inventories and receivables represent $32.20 \%$ of total assets (using median values), with profitability, on average, positive, as median income to total assets (ROA) is equal to $5.7 \%$. Suspect firms exhibit a modified (four-factor, as described in Section 4.2) Z Score of 2.1158 (1.7264 using mean values), while they appear to have met or beaten analysts' consensus forecasts for the past 2.6734 out of four preceding quarters. Interestingly, mean and median changes in leverage are negative during our sample period, indicating minor decreases in the debt carried by our sample suspect firms. Our suspect firm median share of sales volume relative to same industry peers (MarketShare) is observed to be $2.53 \%$ (7.7\% using mean values), with $55.20 \%$ of the firms having NOA above their industry median, and $92 \%$ audited by a BIG4 auditing firm. Marginal tax rates are observed to be around $23 \%$ on average, or $34 \%$ using median values.

All signed discretionary accrual measures exhibit positive values between $0.35 \%$ to $2.6 \%$ of total assets for medians, and $5.3 \%$ to $13.5 \%$ using means. This finding could be considered to be broadly in accordance with previous research observing average DA values around zero at the sample level (Cohen et al. 2008), which would be the expectation for sample average behaviour. Still, the values we observe are on average positive and slightly greater than zero, which could be considered indicative of a possible tendency for upward AM by our sample of suspect firms. Median abnormal discretionary expenses and production costs are also very close to zero on average for our sample of suspect firms, indicating that overall, year and industry controls explain to a significant extent firm expenses and production costs. With respect to RM1, median and especially mean values are positive and higher than zero, as RM1 takes values of about 0.04 using means and 0.02 using medians, which is broadly indicative of a tendency for upward EM by our suspect sample firms. Descriptive statistics for non-suspect firm-year observations are almost identical and we make them available upon request in order to save space.

Table 2 reports pair-wise correlation coefficients between accrual-based earnings management measures and real earnings management measures for all sample suspect firms. Pearson correlation coefficients are reported above the main diagonal and Spearman rank correlation coefficients are reported below the main diagonal. (A_DISEXP) has been multiplied by negative one as in results reported in Table 1 .

Insert Table 2 here. 
Correlations observed in Table 2 generally confirm statistical findings by previous studies, e.g., Cohen and Zarowin (2010) or Roychowdhury (2006). Correlation coefficients fall between $85-90 \%$ or higher for DA estimated under the Jones vs. Modified Jones models, and between roughly $60 \%$ to $80 \%$ for Jones DA and Modified Jones DA versus DA estimated under the Kothari et al. (2005) ROA adjustment approach. Correlations between A_PROD and accruals are positive and significant, and the same applies for correlations between DA and A_DISEXP. All results for our suspect firm sample are consistent with Cohen and Zarowin (2010). ${ }^{13}$ Finally, upward RM metric RM1 positively and significantly correlates with accruals, indicating, without undertaking more detailed analysis until this point, that there exists for our sample suspect firms a possibility for RM to coexist to a certain extent with AM.

\section{Empirical Findings}

6.1 Assessing the Impact of Leverage on AM and RM: Portfolio Analysis

To examine the impact of firm leverage (both different levels of, and changes in, leverage) on $\mathrm{AM}$ and RM, we first examine the median values of AM and RM measures (and their statistical significance) for different leverage portfolios. Each year we construct five portfolios based on the leverage or change in leverage of suspect firms and record the AM and RM measures of the firms in each portfolio. For our sample of suspect firms, Table 3 reports portfolio medians of accrual-based and real earnings management measures, for five annually-rebalanced portfolios of leverage (Panel A) and change in leverage (Panel B). In both Panels, Portfolio 1 consists of the firms with the lowest $L e v_{i, t}$ or $\Delta L e v_{i, t}$ in every year, while Portfolio 5 consists of the firms with the highest.

\section{Insert Table 3 here.}

We observe from Table 3 Panel A that under the Jones and Modified Jones DA estimation models, median DA tend to decrease as we move on from lower to higher leverage portfolios, while median accruals are positively significant for the all debt portfolios. However, we do not observe any such tendency in the case of DA estimated under the Kothari et al. (2005) approach. At the same time, we witness no significant difference in DA experienced between the lowest and highest leverage portfolio for all DA model specifications, which is considered overall indicative of no significant trends with respect to AM behaviour as levels of leverage increase in this univariate sorting.

Results from Table 3 Panel A exhibit opposite trends for RM metrics as we move from lower to higher leverage portfolios for suspect firms. Specifically, abnormal discretionary expenses

\footnotetext{
${ }^{13}$ For a detailed economic rationale of the correlations between AM and RM metrics, see Cohen and Zarowin (2010, p. 9).
} 
(multiplied by minus one, so that higher values indicate upward RM) get negative values for the two bottom debt portfolios (with the value of the bottom leverage portfolio also statistically significant at $1 \%$ ), and positively significant values for the three top debt portfolios. In the case of abnormal production costs, they are negative and significant for the two lowest leverage portfolios, and they obtain positively significant values for the top debt portfolio. Results are further confirmed for the comprehensive RM indicator RM1. RM1 obtains negatively significant values for the two bottom debt portfolios, while its values increase and are consistently positive and significant at the $1 \%$ level for the three higher leverage portfolios. At the same time, for all of A_PROD, A_DISEXP, and RM1, we obtain evidence of strongly significant differences between the bottom and top leverage portfolios, indicating higher values of RM1, A_PROD, and A_DISEXP when comparing the top to the bottom leverage portfolio.

Findings from Table 3 Panel B do not overall contradict the direction of results observed from Panel $\mathrm{A}$ in the case of leverage changes as well. Specifically, we receive indications of downward EM using overproduction as a tool, as the two bottom leverage change portfolios get negative and significant values for A_PROD, with no statistical significance observed for the top debt change portfolios for this variable. RM1 also appears to get higher values for higher leverage change portfolios, and, most importantly, again for all of A_PROD, A_DISEXP, and RM1, we get evidence of strongly significant differences between the bottom and top leverage change portfolios, indicating higher values of RM1, A_PROD, and A_DISEXP when comparing the top to the bottom change in leverage portfolios. With regard to the behaviour of DA as changes in leverage get higher, we do not get any observable trend or association between DA and changes in leverage for either model specification used. However, we do get evidence of the existence of a significantly positive difference in DA experienced between the lowest and highest leverage portfolio for all DA model specifications, which is interestingly indicative of upward AM taking place in the top compared to the bottom - change in leverage portfolio. ${ }^{14}$

Overall, the behaviour of all RM metrics, individual as well as comprehensive, from Table 3 Panels A and B indicates a trend for firms to engage in significant upward RM as debt levels increase, or in the presence of leverage increases, providing confirmation of our first research hypothesis $\mathrm{Hl}$ on higher leverage levels and changes inducing a preference for RM. In the case of AM, there is no trend observed with respect to the behaviour of DA as debt levels increase, and what is observed is that high debt is clearly not accompanied by incomeincreasing AM. However, we do obtain some evidence on the existence of upward AM for

\footnotetext{
${ }^{14}$ Findings from Table 3 (both Panels) remain qualitatively similar when means instead of medians are used, although results (not reported here) are more sensitive to the existence of extreme values. Neither does experimenting with different numbers ( 3 or 10 , etc.) of leverage/leverage change portfolios seem to affect the nature of the results in Table 3 .
} 
firms experiencing very high, as opposed to very low, debt changes. Without any evidence on causality between leverage and EM, portfolio analysis until this point indicates that high levels of debt or changes in debt coincide with higher positive real earnings manipulation, but do not go hand in hand with upward AM in the case of higher debt levels, consistent with our hypotheses. However, we do get some evidence on upward AM for firms experiencing exceptionally strong leverage changes.

A counter argument at this point could be that highly levered firms may experience large negative accruals due to financial trouble (in line with DeAngelo et al. 1994). In this case, the negative accruals observed for highly indebted firms would be simply reflecting bad performance, rather than AM. However, more financially weak firms have been hypothesised to have greater incentives for AM rather than RM, as the cost of deviating from an optimal business strategy is high for these firms (Zang 2012). If firms with poor financial health prefered upward AM, the relevant finding which would confirm such behaviour would be the detection of positive rather than negative DA for these firms. This is not what we find for highly indebted firms, even with the use of accruals which impose some control for firm performance (the Kothari et al. 2005 model).

One could additionally argue here that in the presence of high levels of debt, tight business circumstances could be mistaken for RM, because, for example, firms might exhibit overproduction due to missed demand targets, or decrease discretionary expenses if they face tight debt covenants (Kim et al. 2011). However, our evidence on positive RM is not limited to the most highly indebted firms; rather, it is present in all portfolios in general, as one compares lower vs. higher debt or change in debt. Of course, there is only a limited number of conclusions that can be reached from the one-sort portfolio analysis of this section. Our regression analysis that follows attempts to investigate the effect of leverage on the substitution between AM and RM tactics, after controlling for a number of factors, including financial distress, bad performance or tight industry competition.

It is worth pointing out the contrary effects at hand here. On the one hand, high leverage should be increasing the costs of AM (due to higher outsider scrutiny), thus making RM more probable than AM. On the other hand, however, high leverage could very easily be accompanied by poor financial health, where poor financial health according to Zang (2012) should increase the costs of RM, thus making AM more probable than RM. In this context, the question raised is whether, in the presence of high financial leverage, the expected decreasing effect on RM stemming from the 'financial health' factor is/is not stronger than the expected increasing effect on RM stemming from the 'external scrutiny' factor.

To provide a reply to this question, we have repeated the analysis from Table 3 by recalculating the statistical significance of mean/median proxies for AM and RM for distressed 
suspect vs. healthy suspect firms with different levels of financial leverage. ${ }^{15}$ Following Pryshchepa et al. (2013), distressed firms are considered to be the ones with Altman's Z score $\left(A l t Z_{i, t}\right)$ values $<1.81$, healthy firms the ones with Altman's Z Score values above or equal to 1.81. Relevant results are reported in Table 4, after grouping these firms into one of five leverage $\left(\operatorname{Lev}_{i, t}\right)$ annually rebalanced portfolios. $\left(A_{-} D I S E X P_{i, t}\right)$ has been multiplied by negative one as discussed in Section 3.2.

\section{Insert Table 4 here.}

The purpose of this analysis is to first track the RM and AM patterns of highly leveraged firms with poorer vs. better financial health. In this case, our purpose is to examine whether highly levered firms with better vs. worse financial health differentiate their patterns of use of AM vs. RM, given that low financial health is expected to increase the costs of RM, and thus make AM more probable. At the same time, by repeating this analysis for different leverage quintiles for distressed vs. healthy firms, we examine whether the level of financial leverage combined with financial health plays any role in the level of AM and RM undertaken by firms.

Results from Table 4 indicate a significant tendency of financially healthy firms to engage in upward RM as financial leverage increases, with this tendency not confirmed for distressed firms, with the exception of results on abnormal discretionary expenses. However, as this result for distressed firms is observed only for A_DISEXP and not for any other RM proxy, this could be representative of an effort of such firms to cut costs, rather than indicative of RM. At the same time, in the case of AM, we do not observe any monotonic significant association between AM and differing levels of leverage, depending on whether a firm is considered to be distressed or not. The only weak exception to this finding is evidence on significantly less upward AM when comparing healthy firms from the top vs. bottom leverage portfolio for DA calculated under the Jones (2991) model, confirming less upward AM as leverage increases for this group. Overall, results from Table 4 Panel A indicate that for a suspect firm to be expected to exhibit the AM vs. RM patterns observed in Table 3 for higher vs. lower levels of leverage, in accordance with our first research hypothesis $H 1$, it must not be a financially distressed firm.

Results from Table 4 overall indicate that financially healthy and more strongly leveraged firms will show a greater preference towards RM - confirming our first hypothesis $\mathrm{HI}$ regarding a relative preference for RM as financial leverage increases - compared to counterparts with lower leverage. Stronger vs. weaker financial health is observed to reinforce the preference towards RM, in accordance with Zang (2012). This finding is not confirmed

\footnotetext{
${ }^{15}$ We would like to thank an anonymous reviewer for pinpointing this subtle point and making a detailed and specific suggestion for the type of analysis to follow in order to address this concern.
} 
for distressed firms, so we have here indications that the expected decreasing effect on RM stemming from the 'financial health' factor is indeed stronger than the expected RMincreasing 'external scrutiny' effect if a suspect firm is financially distressed. ${ }^{16}$

\subsection{Assessing the Impact of Leverage on AM and RM: Regression Analysis}

The portfolio analysis of the previous section merely indicates that in the case of suspect firms, high levels of debt or changes in debt coincide with higher positive real earnings manipulation, but do not necessarily coincide with upward accrual-based earnings management. Thus, it provides an indication which cannot be regarded as evidence, in the absence of additional controls. We therefore proceed with the recursive system analysis of equations (1) and (2) outlined in Section 4, that simultaneously controls for the costs associated with both earnings management tactics, as well as other variables.

Panel A of Table 5 summarises the estimation results of equation (1), the first stage of the Heckman procedure, while Panel B of Table 5 summarises the results of the system in (2), the Heckman second stage set of equations.

\section{Insert Table 5 here.}

We observe from the probit first stage results in Panel A that overall, the statistical significance of factors expected to influence the possibility of a firm becoming suspect of meeting or beating earnings targets generally conforms to past research: habitual beaters, firms feeling more pressure from monitoring by analysts or having greater numbers of shares outstanding (as missing earnings-per-share targets usually translates to more dollars of earning shortages for these firms) are the ones which should be significantly expected to be suspect firms for our sample. In contrast, however, to past research, we do not observe a significant influence of the market-to-book ratio or of profitability, on just meeting/beating earnings targets.

The first stage of the Heckman procedure provides the inverse Mill's ratio $\left(I M R_{i, t}\right)$ that is included in the second stage (eq. 2) as a control variable to account for the potential omitted variable problem caused by the non-random nature of our suspect firms sample. Table 5 Panel B summarises the estimation results of the second stage for RM and AM respectively, under the expectation that RM precedes $\mathrm{AM}$ and $\mathrm{AM}$ depends on unexpected levels of RM undertaken during the year, by accounting for cost and benefits for both AM and RM, as well as control factors expected to play a role in firms' decision to engage in EM. We first observe

\footnotetext{
${ }^{16}$ Untabulated results for the analysis reported on Table 4 for changes in leverage are weaker when contrasting AM and RM patterns for distressed vs. healthier firms, indicating that the relative financial health of firms in relation to changes experienced in leverage does not have such a strong impact on the choice of suspect firms to engage in RM vs. AM. Results from Table 4 are qualitatively similar when defining healthy firms as the ones with an Altman's Z score value over 2.99.
} 
from Table 5 Panel B that levels of leverage have a positive and significant (at 10\% level) effect on RM, but no significant effect on RM, consistent with our first hypothesis $H 1$ on a stronger association between leverage and RM rather than AM.

Moreover, we do confirm evidence by Zang (2012) on a substitution effect between unexpected levels of RM and AM, given the sign and significance of the relevant coefficient for Unexpected $R M_{i, t}$. Most interestingly, though, we find that the multiplicative term Lev $_{i, t} \times$ Unexpected $R M_{i, t}$ significantly and positively relates to AM. In line with our second research hypothesis $H 2$, the coefficient of the interaction term is significant even at the $1 \%$ level, indicating that high leverage strongly affects the substitution effect between RM and AM that is established by past research (Zang 2012) for suspect firms. Importantly, a Wald test that is reported in Panel $\mathrm{B}$ on the null hypothesis that $\beta_{5}+\beta_{6} \times \widetilde{\operatorname{Lev}} \leq 0$, i.e. the effect of Unexpected $R M_{i, t}$ for a firm of median leverage $\widetilde{L e v}$ turns from negative $\left(\beta_{5}\right)$ to positive, is clearly rejected at any significance level. In line with our hypothesis $H 2$, the negative association between unexpected RM and AM turns positive, thus transforming a substitution into a complementarity effect for higher levels of leverage. In other words, the presence of high leverage, and the expected monitoring that this has been hypothesised to induce, should be expected to make firms complement AM with RM in an effort to achieve earnings targets, rather than be able to substitute one form of EM with the other in order to attain a specific target.

With respect to the behaviour of the variables used as proxies for cost of AM or RM and control variables, we overall observe some statistical significance. For costs of AM, NOA is found to negatively and significantly relate to $\mathrm{AM}$, as expected, with no observed significance for any other variable. With respect to control variables, the profitability proxy ROA is found to negatively associate to both forms of AM, an indication that EM is undertaken in the presence of performance pressures. At the same time, size and the level of inventories and receivables (Assets and INVRECTA) are found to positively relate to RM, and market-tobook to negatively do so, implying that RM should be more prevalent among larger firms and firms with more inventory and receivables (in accordance with the expectation that large inventories and receivables may provide higher flexibility to engage in RM according to Roychowdhury 2006) and firms with lower growth. However, none of these control variables is observed to exhibit any statistical significance in the AM equation. At the same time, we observe that the inverse Mill's ratio $\left(I M R_{i, t}\right)$ is highly significant in the RM equation, but very insignificant in the $\mathrm{AM}$ equation, indicating that suspect firm status has a significant (and positive) effect on undertaking RM but not AM. This is consistent with suspect firms being more prone to engage in RM rather than AM, the latter being generally considered to be more easily scrutinised by parties outside the firm. Moreover, the variance inflation factors 
for selected independent variables that are reported in Panel B are very low, suggesting that no multicollinearity problems plague our specifications. ${ }^{17}$

To further assess the effects of leverage and RM (and their interaction) on the substitution/complementarity of earnings management tactics, we re-estimate the second stage of the Heckman procedure by replacing the leverage continuous variable $L e v_{i, t}$ wherever it appears (as a stand-alone regressor or in the interaction term) with the sum of five multiplicative terms Lev $\operatorname{Lit}_{i, t} \times \mathbf{1}_{\text {Quantile }=q}, q=\{1,2,3,4,5\}$. The indicator function $\mathbf{1}_{\text {Quantile }=q}$ takes the value of one if the leverage of suspect firm $i$ in year $t$ belongs to the $q^{\text {th }}$ leverage quantile over the sample period, and zero otherwise. ${ }^{18}$ This re-estimation, the results of which are summarised in Table 6, is performed in order to account for the effect of different levels of leverage on the substitution of AM with $\mathrm{RM}$ and to investigate whether the complementarity effect observed in the results of Table 5 is uniform across all leverage levels.

\section{Insert Table 6 here.}

We observe from the results reported in Table 6 that in three out of five cases, (corresponding to relevant leverage quintile indicator variables), including the highest two leverage portfolios, the multiplicative term $\operatorname{Lev}_{i, t} \times \mathbf{1}_{\text {Quantile }=q}$ is both positive and statistically significant, while the same variable shows no signs of significance in the AM regression. This finding confirms our first research hypothesis $H 1$, but this time by taking into account differing amounts of leverage. Unexpected RM is again negatively significant in the AM regression, while this variable multiplied by $\operatorname{Lev}_{i, t} \times \mathbf{1}_{\text {Quantile }=q}$ is observed to be statistically significant and positive only in the case of the highest leverage portfolio. This latter is in complete accordance with $H 2$ and is further confirmed by the reported Wald test on the combined effect of unexpected RM for the top leverage quintile (the only one reported for the sake of brevity). In this way, taken as a whole, results from Tables 5 and 6 indicate that leverage plays a role in the determination of RM but not AM. At the same time, leverage will tend to turn the trade-off observed by past research between unexpected levels of RM and RM into a complementarity effect, in a need to combine both forms of EM in order to achieve earnings targets, with this result mainly driven by firms with the highest levels of leverage, that is, firms expected to induce the highest levels of scrutiny and monitoring by outside interest groups.

We repeat the analysis for different levels of leverage, this time for changes in leverage $\Delta L e v_{i, t}$. Table 7 reports results of an analysis similar to that of Table 6, this time replacing the five quintile indicators of $L e v_{t}$ with relevant quintile indicators $\mathbf{1}_{\Delta Q u a n t i l e=q}$ for changes in

\footnotetext{
${ }^{17}$ Multicollinearity is considered to be low when the variance inflation factors (VIFs) are below a ruleof-thumb threshold value of 10 (see for example Chatterjee and Hadi 2012).

${ }^{18}$ The first stage Heckman equation is the same as in Table 5.
} 
leverage $\left(\Delta L e v_{t}\right)$ (from lowest to highest), and multiplying these variables with the change in leverage indicator and the Unexpected RM proxy.

\section{Insert Table 7 here.}

We observe from Table 7 that the change in leverage variable, multiplied by dummy variables indicative of change in leverage magnitude $\left(\Delta L e v_{t} \times \mathbf{1}_{\Delta \text { Quantile }=q}, q=\{1,2,3,4,5\}\right)$, is positive and statistically significant at $5 \%$ level only in the case of the top $\Delta L e v_{t}$ portfolio in the RM regression, indicating that very strong changes in leverage do induce upward RM. This is not the case, however, for lower leverage changes. Thus, our first research Hypothesis $H 1$ is confirmed for changes, in addition to levels of leverage. The Unexpected $R M_{t}$ regressor is again negatively significant in the AM equation in the case of the changes results, as has been the case for Tables 5 and 6 for levels, indicating a trade-off between unexpected $\mathrm{RM}$ and $\mathrm{AM}$ in general. Interestingly, while none of the $\Delta L e v_{t} \times \mathbf{1}_{\Delta \text { Quantile } 1 \text { to } 5}$ regressors is significant for any of the lower 4 change in leverage portfolios in the AM regression, this multiplicative term is negatively significant for the top $\Delta L e v_{t}$ portfolio in the AM equation, indicating that high leverage changes negatively affect the choice to proceed with AM. This result is qualitatively opposite from the relevant result for RM in the presence of significant leverage changes. At the same time, in the case of the AM equation, we observe that again the multiplicative term $\Delta L e v_{t} \times$ Unexp. $R M_{t} \times \mathbf{1}_{\Delta \text { Quantile } 1 \text { to } 5}$ is positively statistically significant only for the top change-in-leverage portfolio This is indicative that very high changes in leverage (but not changes of lower magnitude) induce a complementarity effect between unexpected RM and AM, as has been the case for very high levels of leverage, providing further confirmation for $\mathrm{H} 2$ in the case of changes in leverage. With respect to the behaviour of the rest of regressors, this is in the same direction as for relevant results from Tables 5 and 6 for levels of debt.

Findings from Tables 3 to 7 for firms suspect of having managed earnings in an effort to achieve earnings targets are overall indicative of higher vs. lower levels of leverage (or changes in leverage) being associated with higher EM based on real transactions, and no obvious or significant AM behaviour pattern depending on different levels or changes in debt. Regression analysis further explicitly indicates that very high (but not lower) levels of leverage (and changes in leverage) positively and significantly affect the decision to engage in RM The relevant association between debt levels and changes and AM are not so clear or overall significant (with the exception of strong changes in leverage, negatively and significantly relating to levels of AM). At the same time, we do confirm the existence of a trade-off between higher levels of unexpected RM undertaken during the whole financial year and AM in accordance with past research (Zang 2012). However, our findings are consistent with this substitution effect turning into a complementarity effect between unexpected RM 
and AM for firms experiencing the highest levels or changes in debt. In this respect, both our hypotheses $H 1$ and $H 2$ are observed to be confirmed by findings reported in Tables 3 to 7 following evidence of a positive and significant association between leverage levels (and changes) and RM, a non-significant effect of leverage levels on AM, and a significant complementarity effect observed between AM and unexpected levels of RM observed for the most highly levered firms. We interpret the latter finding as indicative of firms complementing AM with RM in an effort to achieve earnings targets in the presence of strong leverage levels and changes, as the expected monitoring that a strong presence of debt has been hypothesised to induce puts firms in a position where they have to complement, rather than being able to substitute, one form of EM with the other in an effort to attain a specific target for its earnings.

6.3 The Impact of EM and Different Levels of Leverage and Changes in Leverage on Subsequent Market Performance

To examine the association between earnings management, different levels of debt, as well as debt changes, and subsequent market performance, we need an empirical setting simultaneously controlling for levels of debt and EM. We therefore construct 9 portfolios for each year for our sample firms, using (a) firms' leverage and (b) firms' earnings management (real and accrual-based) metrics, for observations falling into the bottom $30 \%$, middle $40 \%$ or top $30 \%$ of total suspect firm-year observations. For each portfolio that is formed every year $t$, we record its equally-weighted buy-and-hold abnormal return (BHAR) over a period that starts in April of year $t+1$ and lasts for $l$ months (i.e., an $l$-month window). We leave a fourmonth period after the fiscal year-end before calculating BHARs for the public announcement of financial results to take place. With respect to the buy-and-hold abnormal return calculation, we follow Barber and Lyon (1997) and define BHARs as:

$$
B H A R_{l}=\prod_{t=1}^{l}\left(1+R_{i, t}\right)-\prod_{t=1}^{l}\left(1+R_{\text {benchmark }, t}\right)
$$

Each suspect firm is matched each sample year with a control firm of similar size and bookto-market ratio as outlined in Barber and Lyon (1997), and the control firm's buy-and-hold return acts as the benchmark return in equation (3) of the text. ${ }^{19}$ Data on firm monthly stock returns (including dividends), book-to-market ratios and market values are downloaded from CRSP.

In Table 8, we report median 3, 12 and 24-month-ahead BHARs of the 9 leverage and EM metrics portfolios $(l=3,12$ and 24 in Panels A, B, and C of the Table, respectively, from

\footnotetext{
19 As Barber and Lyon (1997, p.370) point out, matching sample firms to control firms on specified firm characteristics such as size and book-to-market alleviates known biases in abnormal return calculation (such as the new listing bias, the rebalancing bias, and the skewness bias), especially for longer time horizons. We would like to thank an anonymous reviewer for underlining this last point.
} 
April $t+1)$. The EM metrics used are $\mathrm{RM} 1_{i, t}$ for real earnings management and discretionary accruals under the Modified Jones specification are used as proxies for AM. Table 8 also reports the statistical significance of median portfolio returns. In addition, in rows/columns entitled $\mathrm{H}_{0}$ : Equal Medians, we report ('high' minus 'low') portfolio BHAR differences in medians, with z-statistics from Wilcoxon rank sum tests (under the null hypothesis that Portfolios 3 and 1 are from distributions with equal medians) in square brackets.

\section{Insert Table 8 here.}

We observe from the results of Table 8 that RM in relation to levels of leverage does not appear to be consistently associated with any significant effect on abnormal market performance, for all 3-, 12- and 24-month investment windows. The tests for the equality of medians between the bottom and top RM portfolio for a given level of leverage indicate confirmation that performance is actually comparable between them. The same generally applies to the tests of median equality between the 'low' and 'high' leverage portfolios, for any given level of RM. So, positive RM in relation to leverage does not seem to result in consistent differences between firms in terms of stock market performance, for the following 3 to 24 months.

However, the contrary appears to be the case with respect to AM and leverage portfolios, at least in the short-run. We observe a tendency for significant deterioration of performance as we move from lower to higher AM portfolios, keeping levels of leverage constant for the 3month return window in Panel A of the Table. The differences in stock performance between the bottom and top AM portfolios for any given level of leverage are in every case significant for the 3-month window, indicating that for a given level of leverage, a firm engaging in upward AM will perform worse than a firm not doing so, i.e., the market is found to penalise for this behaviour, on a risk-adjusted basis over the next three months following financial reporting. However, we do not observe such a pattern for returns from the 12-month window onwards, indicating that the market should have fully incorporated information on EM by that time, resulting in no further penalisation of higher AM firms for a given level of leverage. Regarding patterns in returns as we move from lower to higher leverage portfolios for a given level of AM, overall we do not observe any significant or trend-indicating pattern. Finally, a casual comparison permits one to observe that when significant, differences in the level of BHARs for firms with a given level of leverage are larger (in absolute terms) for AM compared to RM. As a whole, results for AM indicate that investors tend to heavily penalise for the use of AM at least in the short run, but not for RM. This relative absence of penalisation for RM confirms our third hypothesis $H 3$, which expects greater difficulties in detection of RM vs. AM undertaken in relation to leverage. This evidence is interpreted as a 
possible indication of the ability of investors to see through AM tactics, particularly for shorter time horizons.

In Table A1 of Appendix A, we repeat the analysis reported in Table 4 for AM and RM in relation to leverage levels as well as financial health, by tracking this time the market performance for sample (suspect) firms with Altman's $Z$ score $\left(A l t Z_{i, t}\right)$ values $<1.81$ ('Distressed firms') and Z Score values above 1.81 ('Healthy firms'), grouped into one of five leverage $\left(L e v_{i, t}\right)$ annually rebalanced portfolios. Market performance is estimated for the next 3, 12 and 24 months after portfolio formation using buy-and-hold abnormal returns (BHARs). The scope of this analysis is to examine whether financial health plays a differential role with respect to market appraisal in the presence of different levels of leverage, and especially, high financial leverage, and in this way track the market performance of firms with differing levels of leverage examined in Table 4.

We generally observe from Table A1 in Appendix A that for a given level of leverage, market performance tends to be significantly stronger for more vs. less financially healthy firms, and this result tends to hold for all time windows examined. At the same time, more (vs. less) financially healthy, highly-levered firms tend to have significantly higher returns over the next 3, 12 and 24 months after portfolio formation, which is consistent with market participants compensating for good financial performance through their market return formation patterns. A notable exception to these findings is the significantly higher return for the most levered distressed firms, in comparison to healthy ones, for the shorter (3-month) time window examined. This result reverses for the 12 and 24-month time windows, and is interpreted as an indication of market compensation for highly levered and distressed firms' risk in the short-term, with the relevant result dissipating for longer time windows, over which financial health is more positively compensated.

Table 9 finally reports median 3-, 12- and 24-month BHARs for 9 change-in-leverage and EM metrics portfolios $(1=3,12$ and 24 in Panels A, B, and C of the Table, respectively, from April $t+1)$. The EM metrics used are again $\mathrm{RM} 1_{i, t}$ for $\mathrm{RM}$ and discretionary accruals under the Modified Jones specification are used as proxies for AM

\section{Insert Table 9 here.}

Results from Table 8 on the behaviour of stock returns depending on different levels of leverage and EM levels are generally confirmed from Table 9 in the case of changes in leverage, providing support for our third hypothesis $H 3$ of changes in leverage, in addition to levels, inducing $\mathrm{AM}$ as opposed to RM by EM suspect firms. RM in relation to leverage changes does not appear to be consistently associated with any significant effect on market performance, for any investment horizon. In the case of AM, however, we observe the same 
type of difference to be consistently statistically significant (and negative) for the 3-month return window. ${ }^{20}$

Overall, the findings of the portfolio analysis from Tables 8 and 9 confirm our third research hypothesis $\mathrm{H} 3$ and suggest that investors appear to more heavily and readily penalise accrualbased debt-induced EM. The stock market reaction to real EM, which is expected to be more difficult to detect, is not significantly negative in relation to observed differences in levels of leverage or changes in debt. In the case of stock market reaction to AM by market participants, however, we observe a significant penalisation of AM for a given level of change in leverage, indicating that equity investors may manage to see through high levels of AM for a given level or change in leverage, and negatively price such actions through return formation.

\section{Concluding Remarks}

In this study, we examine whether the level of, and increases in, financial leverage have an impact on the use of accrual-based and real earnings management tactics. We hypothesise that in cases where firms engage in EM in order to achieve earnings targets in the presence of significant levels of debt or large increases in debt, RM should be their preferred choice because of a lower possibility - and subsequent costs - of getting caught, given that RM does not involve accrual manipulation but can rather 'be masked' in the form of everyday transactions. According to the control hypothesis by Jensen (1986), leverage should be expected to bring increased monitoring and scrutiny on the part of outside creditors, with this expectation equally extrapolated to any outside party with an investment interest in the firm, including equity investors interested in assessing firms' risk profiles.

We use all non-financial firms from Compustat during 1990-2009 and first establish that higher levels of leverage (or changes in leverage) positively and significantly associate with higher levels of upward RM. However, we observe no relevant evidence for the existence of upward AM in the presence of higher levels of debt or changes in such, while these conclusions are deduced for all firms with an assumed motivation to engage in EM in order to avoid reporting a loss, or a decrease in earnings from previous year levels, or miss an earnings target set by financial analysts. We then confirm that AM is undertaken sequentially to RM, confirming past research (Zang 2012, Chan et al. 2015), and implement regression analysis pointing towards leverage (levels and changes) having a significantly positive effect on RM, but no significant influence on AM, with the former effect being stronger for higher levels of leverage. Most interestingly, our findings indicate the existence of a complementarity effect

\footnotetext{
${ }^{20}$ Untabulated results are qualitatively the same with the use of means, for both Tables 8 and 9. (Untabulated) results when using a 6-month window are qualitatively similar (although weaker) in comparison to results for the 3 -month window, for both Tables 8 and 9.
} 
between unexpected levels of RM and AM, which becomes very strong in the case of highly indebted firms (or firms experiencing very high leverage changes). We thus provide evidence that in the presence of high levels of leverage (or changes in debt), the trade-off effect between RM and AM (Zang 2012) turns into a complementarity effect. This evidence is interpreted as an indication that very high leverage is accompanied by strong outsider scrutiny, making it necessary for firms to use RM in combination with AM to be able to achieve earnings targets.

We additionally examine the impact of leverage-induced RM and AM on the perceptions of investors regarding suspect firms, which are assumed to materialise through market appraisal in the case of equity investors, in an effort to assess whether market pricing can see through EM practices. Our focus on the consequences of leverage-induced EM is based on the investor group whose reaction should be the quickest to capture, that is, equity investors. We assess buy-and-hold abnormal returns for double-sorted portfolios formed on the basis of the amount of firm AM or RM metrics observed in a given year and the level of firm leverage (and leverage change) in that year, and find evidence that for a given level of leverage, there exists a significantly negative association between AM and subsequent stock returns in the 3 months after portfolio formation, while this phenomenon is observed to dissipate for horizons of one year and beyond. In contrast, firms using income-increasing RM when compared to firms with equal debt burdens that refrain from RM are found to have indistinguishable stock market performance over the subsequent 3 to 24 months, while all previous findings hold when repeating the analysis for changes in leverage. These findings lead to the conclusion that stock market investors appear to penalise more heavily and readily debt-induced AM rather than RM, which is interpreted as an indication that AM can be more easily detected than RM.

Our study contributes to past research by providing evidence for the first time that leverage and changes in leverage have a significantly positive impact on upward RM as opposed to AM for firms with earnings targets in place. These findings provide evidence that an environment of increased monitoring and scrutiny indeed supports a preference for RM over AM. However, the main difference between the debt and equity capital providers lies in the fact that, in contrast to shareholders, even if investment risks increase, debt-holders are not residual claimants and are by definition more concerned with receiving repayment of their capital and interest, rather than maximising the value of the firm. Consequently, an alternative interpretation for our findings could be that the positive relationship between debt and RM (but not AM) observed by this study may instead reflect debt-holders' preference, and thus may not constitute purely a choice of EM practice, but rather a strategy of value transfer and risk redistribution from debt-holders to equity holders. 
At the same time, we provide evidence that the substitution effect between unexpected levels of RM and AM ascertained by past research (Zang 2012) may turn into a complementarity effect for very high levels of leverage. Thus, very high levels of leverage (or relevant increases) could make firms unable to achieve earnings targets by relying only on one method of EM, so they have to complement one form with the other. The existence of high levels of (or increases in) financial leverage is expected to inherently result in differential levels of information between information-sharing insiders and different groups of outsiders, that is debt vs. equity holders. This provides the framing for the examination of our research questions within the revelation theory, which predicts that EM is possible when a number of perfect market conditions hold (Alhadab et al. 2015, Walker 2013).

Finally, we find that leverage-induced AM is significantly more negatively penalised by market participants than relevant RM undertaken in relation to leverage (or changes in leverage), at least for a number of months after engaging in such practices. This evidence could be broadly consistent with findings by Badertscher (2011) that firms use RM to sustain their overvaluation. We consider that our evidence on the market-value consequences of debtinduced AM and RM - which could be undertaken in the course of efforts to achieve earnings targets - provides a better understanding of the range of possible consequences of leverage. This is because such consequences of leverage-related EM could be incremental to other problems that debt may induce for corporate actions, e.g., underinvestment, and knowledge of such behaviour would be of interest for any party engaging in a lending or business transactions with the firm, or interested in investing in the firm. Thus, we consider that our evidence that market participants seem to under-react to RM but not to AM provides a better understanding of the economic consequences of RM vs. AM, with respect to ease of detection and formation of expectations about the future economic performance of firms accordingly.

\section{References}

Alhadab, M., Clacher, I., and Keasey, K. 2015. Real and accrual earnings management and IPO failure risk. Accounting and Business Research, 45 (1), 55-92

Altman, E., 1968. Financial ratios, discriminate analysis and the prediction of corporate bankruptcy. Journal of Finance, 23 (4), 589-609.

Arya, A., Glover, J. and Sunder, S., 1998. Earnings management and the revelation principle. Review of Accounting Studies, 3 (1/2), 7-34.

Badertscher, B., 2011. Overvaluation and the choice of alternative earnings management mechanisms. Accounting Review, 86 (6), 1935-1967.

Ball, R. and Shivakumar, L., 2006. The role of accruals in asymmetrically timely gain and loss recognition. Journal of Accounting Research, 44 (2), 207-242. 
Barber, B. M. and Lyon, J. D., 1997. Detecting long-run abnormal stock returns: The empirical power and specification of test statistics. Journal of Financial Economics, 43 (3), 341-372.

Bartov, E., 1993. The timing of assets sales and earnings manipulation. Accounting Review, 68 (4), 840-855.

Beatty, A. and Webber, J. 2003. The effects of debt contracting on voluntary accounting method changes. Accounting Review, 78 (1), 119-142.

Becker, C., DeFond, M., Jiambalvo J. and Subramanyam, K., 1998. The effect of audit quality on earnings management. Contemporary Accounting Research, 15 (1), 1-24.

Beyer, A., Cohen, D. A., Lys, T. Z. and Walther, B. R., 2010. The financial reporting environment: Review of the recent literature. Journal of Accounting and Economics, 50(2), 296-343.

Bhojraj, S., Hribar, P., Picconi M. and McInnis, J., 2009. Making sense of cents: an examination of firms that marginally miss or beat analyst forecasts. Journal of Finance, 64 (5), 2359-2386

Bradshaw, M., Richardson S. and Sloan, R., 2006. The relation between corporate financing activities, analysts forecasts and stock returns. Journal of Accounting and Economics, 42 (12), 53-85.

Cai, J. and Zhang, S., 2011. Leverage change, debt overhang, and stock prices. Journal of Corporate Finance, 17 (3), 391-402.

Chan, L.H, Chen, K.C.W., Chen, T.-Y.C and Yu, Y., 2015. Substitution between real and accruals-based earnings management after voluntary adoption of compensation clawback provisions. Accounting Review, The Accounting Review, 90 (1), 147-174.

Chatterjee, S. and Hadi, A. S., 2012. Regression Analysis by Example, $5^{\text {th }}$ edition, New York: Hoboken, NJ.

Chung, R., Firth, M. and Kim, J.-B., 2005. Earnings management, surplus free cash flow, and external monitoring. Journal of Business Research, 58 (6), 766-776.

Cohen, D., Dey A. and Lys, T., 2008. Real and accrual-based earnings management in the pre- and post- Sarbanes Oxley period. Accounting Review, 83 (3), 757-787.

Cohen, D. and Lys, T., 2006. Weighing the evidence on the relation between external corporate financing activities, accruals and stock returns. Journal of Accounting and Economics, 42 (1-2), 87-105. 
Cohen, D. and Zarowin, P., 2010. Accrual-based and real earnings management activities around seasoned equity offerings. Journal of Accounting and Economics, 50 (1), 2-19.

DeAngelo, H., DeAngelo, L. and D. Skinner. 1994. Accounting choice in troubled companies. Journal of Accounting and Economics, 17 (1), 113-143.

Dechow,. P., Sloan R. and Sweeney, A., 1995. Detecting earnings management. Accounting Review, 70 (2), 193-225.

DeFond, M. and Jiambalvo, J., 1994. Debt covenant violation and manipulation of accruals. Journal of Accounting and Economics, 17 (1-2), 145-76.

DeFond, M. and Park, C., 1997. Smoothing income in anticipation of future earnings. Journal of Accounting and Economics, 23 (2), 115-139.

Dimitrov, V. and Jain, P., 2008. The value-relevance of changes in financial leverage beyond growth in assets and GAAP earnings. Journal of Accounting, Auditing and Finance, 23 (2), 191-222.

Dye, R., 1988. Earnings management in an overlapping generations model. Journal of Accounting Research, 26 (2), 195-235.

Fama, E. and French, K., 1993. Common risk factors in the returns on stocks and bonds. Journal of Financial Economics, 33 (1), 3-56.

Fields, T., Lys T. and Vincent, L., 2001. Empirical research on accounting choice. Journal of Accounting and Economics, 31 (1-3), 255-308.

Graham, J., 1996a. Debt and the marginal tax rate. Journal of Financial Economics, 41 (1), 41-73.

Graham, J., 1996b. Proxies for the corporate marginal tax rate. Journal of Financial Economics, 42 (2), 187-221.

Graham, J., and Mills, L., 2008. Simulating marginal tax rates using tax return data. Journal of Accounting and Economics, 46 (2-3), 366-388.

Graham, J., Harvey C. and Rajgopal, S., 2005. The economic implications of corporate financial reporting. Journal of Accounting and Economics, 40 (1-3), 3-73.

Graham, J., Li, S. and Qiu, J., 2008. Corporate misreporting and bank loan contracting. Journal of Financial Economics, 89 (1), 44-61.

Gu, F., 2008. Discussion of the value-relevance of changes in financial leverage beyond growth in assets and GAAP earnings. Journal of Accounting, Auditing and Finance, 23 (2), 223-232. 
Gunny, K. A., 2010. The relation between earnings management using real activities manipulation and future performance: evidence from meeting earnings benchmarks. Contemporary Accounting Research, 27 (3), 855-888.

Hausman, J. A., 1978. Specification tests in econometrics. Econometrica, 46(6), 1251-1271.

Heckman, J. J., 1979. Sample selection bias as a specification error. Econometrica, 47 (1), 153-161.

Jaggi, B. and Lee, P., 2002. Earnings management response to debt covenant violations and debt restructuring. Journal of Accounting, Auditing, and Finance, 17 (4), 295-324.

Jelinek, K., 2007. The effect of Leverage Increases on Earnings Management. Journal of Business and Economic Studies, 13 (2), 24-46.

Jensen, M.C,. 1986. Agency costs of free cash flow, corporate finance, and takeovers. American Economic Review, 76 (2), 323-329.

Jones, J., 1991. Earnings management during import relief investigations. Journal of Accounting Research, 29 (2), 193-228.

Kim, B.-H., Lisic, L.-L. and Pevzner, M., 2011. Debt covenant slack and real earnings management. Working paper, SSRN.

Kothari, S.P., Leone, A.J. and Wasley, C., 2005. Performance-matched discretionary accrual measures. Journal of Accounting and Economics, 39 (1), 163-97.

Larcker, D. and Richardson, S., 2004. Fees paid to audit firms, accrual choices, and corporate governance. Journal of Accounting Research, 42 (3), 625-658.

Lee, K.W., Lev B., and Yeo G., 2007. Organizational structure and earnings management. Journal of Accounting, Auditing and Finance, 22 (2), 293-331.

McNichols. M., 2000. Research design issues in earnings management studies. Journal of Accounting and Public Policy, 19 (4-5), 313-345.

Mohd Saleh, N. and Ahmed, K., 2005. Earnings management of distressed firms during debt renegotiation. Accounting and Business Research, 35 (1), 69-86.

Myers, S., 1977. Determinants of corporate borrowing. Journal of Financial Economics, 5 (2), 147-175.

Nwaeze, E., Yang S. and Yin, J., 2006. Accounting information and CEO compensation: the role of cash flow from operations in the presence of earnings. Contemporary Accounting Research, 23 (1), 227-265. 
Penman, S., Richardson, S. and Tuna, I., 2007. The book-to-price effect in stock returns: accounting for leverage. Journal of Accounting Research, 45 (2), 427-467.

Piotrosky, J., 2007. Discussion of the book-to-price effect in stock returns: accounting for leverage. Journal of Accounting Research, 45 (2), 4269-479.

Pryshchepa, O., Aretz, K. and Banerjee, S. 2013. Can investors restrict managerial behavior in distressed firms? Journal of Corporate Finance, 23, 223-239.

Rodríguez-Pérez, G. and van Hemmen, S., 2010. Debt, diversification and earnings management. Journal of Accounting and Public Policy, 29 (2), 138-159.

Ronen, J. and Yaari, V., 2008. Earnings Management: Merging Insights in Theory, Practice and Research. New York, NY: Springer Series in Accounting Scholarship Volume 3.

Roychowdhury, S., 2006. Earnings management through real activities manipulation. Journal of Accounting and Economics, 42 (3), 335-370.

Sweeney, A., 1994. Debt-covenant violations and managers' accounting responses. Journal of Accounting and Economics, 17 (3), 281-308.

Trueman, B. and Titman,S., 1988. An explanation for accounting income smoothing. Journal of Accounting Research, 36 (Supplement), 127-139.

Vella, F., 1998. Estimating models with sample selection bias: A Survey, Journal of Human Resources, 33(1), 127-169.

Walker, M. 2013. How far can we trust earnings numbers? What research tells us about earnings management. Accounting and Business Research, 43 (4), 445-481.

Watts, R. and Zimmerman. J., 1986. Positive Accounting Theory. New Jersey: Prentice Hall.

Watts, R. and Zimmerman, J., 1990. Positive accounting theory: a ten year perspective. Accounting Review, 65 (1), 131-156.

Wooldridge, J. M., 2002. Econometric Analysis of Cross Section and Panel Data. Cambridge, MA: The MIT Press.

Zang, A., 2012. Evidence on the trade-off between real activities manipulation and accrualbased earnings management. Accounting Review, 87 (2), 675-803.

Zhao, Y. and Chen, K., 2008. The influence of takeover protection on earnings management. Journal of Business Finance and Accounting, 35 (3-4), 347-375.

Zhong, K., Gribbin, D. and Zheng, X., 2007. The effect of monitoring by outside blockholders on earnings management. Quarterly Journal of Business and Economics, 46 (1), 37-60. 
Table 1: Sample Descriptive Statistics. The table reports summary statistics for the sample of suspect firm-year observations (as defined in Section 4.1) with accounting data on Compustat during 1990-2009. The sample consists of common stocks traded on the NYSE, AMEX, and NASDAQ, excluding financials (two-digit SIC codes 6000s) and regulated industries (two-digit SIC codes 4400-5000). The Table reports statistics for the debt ratio $\left(L e v_{i, t}\right)$ and the change in the debt ratio $\left.\Delta L e v_{i, t}\right)$, the operating cycle $\left(C_{C y c l e}, t\right)$, profitability $\left(R O A_{i, t}\right)$, Altman's Z Score $\left(Z_{\text {Score }}{ }_{i, t}\right)$, the log of total assets used as a size proxy $\left(\right.$ Assets $\left._{i, t}\right)$, the market-to-book ratio $\left(M t o B_{i, t}\right)$, the marginal tax rates $\left(M T R_{i, t}\right)$, market share $\left(\right.$ MarketShare $_{i, t}$ ), number of times of beating/meeting analysts' consensus forecast from $\mathrm{I} / \mathrm{B} / \mathrm{E} / \mathrm{S}$ in the past four quarters $\left(\mathrm{HabBeat}_{i, t}\right)$, the ratio of inventories and receivables as a percentage of total assets $\left(I N V R E C T A_{i, t}\right)$, the log of 1 plus the number of analysts following the firm ( AnalystFollow $_{i, t}$ ), the log of the number of shares outstanding (Shares $\left.i, t\right)$, and the $\%$ of firms with net operating assets above industry-year median for a given year $\left(N O A_{i, t}\right)$ and the $\%$ of firms with a BIG4 auditor $\left(B I G_{i, t}\right)$. All variables have been calculated as defined in Section 4.2. For a suspect firm-year observation to be included in Table 1 (as well as in all subsequent analyses), it must have (post-truncation) a leverage ratio $\operatorname{Lev}_{i, t}<10$. The table also reports information for (signed) discretionary accruals, according to the Modified Jones, Jones and Kothari specifications, and also abnormal discretionary expenses ( $\left.A_{-} D I S E X P_{i, t}\right)$ and abnormal production costs $\left(A_{-} P R O D_{i, t}\right)$, and $\mathrm{RM} 1_{\mathrm{i}, \mathrm{t}}$. For comparability purposes with other RM measures, $\left(A_{-} D I S E X P_{i, t}\right)$ has been multiplied by negative one, so that the higher the value of this variable, the greater the possibility for a firm to engage in upward RM.

\begin{tabular}{|c|c|c|c|c|c|c|}
\hline Variables & No. Obs. & Q1 & Mean & Median & Q3 & St. Dev. \\
\hline \multicolumn{7}{|l|}{ Controls } \\
\hline$L e v_{i, t}=T D_{i, t} / T A_{i, t}$ & 4,675 & 0.0933 & 0.4424 & 0.2175 & 0.3674 & 1.0954 \\
\hline$\Delta L e v_{i, t}$ & 4,257 & -0.0596 & -1.7998 & -0.0137 & 0.0288 & 17.5483 \\
\hline Cycle $_{i, t}$ & 4,455 & 36.7120 & 93.3174 & 74.3560 & 126.1810 & 188.4593 \\
\hline$R O A_{i, t}$ & 4,469 & 0.0196 & 1.6485 & 0.0570 & 0.0936 & 11.6836 \\
\hline ZScore $_{i, t}$ & 4,520 & 1.3408 & 1.7264 & 2.1158 & 2.7995 & 3.7094 \\
\hline $\operatorname{Ln}\left(T A_{i, t}\right)$ & 4,675 & 11.3836 & 12.0786 & 12.3427 & 13.0996 & 1.3299 \\
\hline$M V_{i, t} / B V_{i, t}$ & 4,262 & 1.4563 & 3.0310 & 2.2885 & 3.6141 & 3.0259 \\
\hline$M T R_{i, t}$ & 3,804 & 0.0287 & 0.2293 & 0.3400 & 0.3500 & 0.1511 \\
\hline MShare $_{i, t}$ & 4,060 & 0.0069 & 0.0770 & 0.0253 & 0.0854 & 0.1357 \\
\hline HabitBeater $_{i, t}$ & 4,348 & 2.0000 & 2.6734 & 3.0000 & 4.0000 & 1.1623 \\
\hline$I_{N V R E C T A}{ }_{i, t}$ & 4,576 & 0.1824 & 5.8368 & 0.3220 & 0.4855 & 34.7694 \\
\hline Ln(AnalystFollowing $\left.{ }_{i, t}\right)$ & 4,388 & 1.0986 & 1.7354 & 1.7918 & 2.1972 & 0.6554 \\
\hline $\operatorname{Ln}\left(\right.$ Shares $\left._{i, t}\right)$ & 4,570 & 9.4913 & 10.2356 & 10.1752 & 10.9248 & 1.0737 \\
\hline \multicolumn{7}{|l|}{ Accrual-based EM } \\
\hline$D A M J_{i, t}$ (M. Jones) & 3,472 & -0.0330 & 0.1350 & 0.0247 & 0.1203 & 0.5771 \\
\hline$D A J_{i, t}($ Jones $)$ & 3,553 & -0.0322 & 0.1297 & 0.0257 & 0.1233 & 0.5273 \\
\hline$D A K_{i, t}($ Kothari $)$ & 3,474 & -0.0504 & 0.0528 & 0.0035 & 0.0748 & 0.2851 \\
\hline \multicolumn{7}{|l|}{ Real EM } \\
\hline$A \_D I S E X P_{i, t}$ & 3,615 & -0.1458 & 0.0342 & 0.0162 & 0.1899 & 0.7327 \\
\hline$A \_P R O D_{i, t}$ & 3,041 & -0.1507 & 0.0031 & -0.0201 & 0.1330 & 0.3440 \\
\hline$R M 1_{i, t}$ & 2,861 & -0.2611 & 0.0417 & 0.0207 & 0.3015 & 0.6723 \\
\hline \multicolumn{7}{|l|}{ Dummy vars (\% firms with) } \\
\hline$N O A_{i, t}>$ Industry Median & 3,538 & & 0.5520 & & & 0.4974 \\
\hline Auditor $B I G_{i, t}$ & 4,675 & & 0.9204 & & & 0.2707 \\
\hline
\end{tabular}


Table 2: Correlation Coefficients. The table reports pair-wise correlation coefficients between accrual-based earnings management measures and real earnings management measures for the sample suspect firms (defined in Section 4.1). Pearson correlation coefficients are reported above the main diagonal and Spearman rank correlation coefficients are reported below the main diagonal. For comparability purposes with other RM measures, $\left(A_{-} D I S E X P_{i, t}\right)$ has been multiplied by negative one, so that the higher the value of this variable, the greater the possibility that a firm is engaging in upward RM. Asterisks $* * *$ and $* * *$ indicate statistical significance at the $10 \%, 5 \%$ and $1 \%$ level respectively.

\begin{tabular}{|c|c|c|c|c|c|c|}
\hline & $R M 1_{i, t}$ & $A \_D I S E X P_{i, t}$ & $A_{-} P R O D_{i, t}$ & $\begin{array}{c}D A M J_{i, t} \\
\text { (M. Jones) }\end{array}$ & $\begin{array}{r}D A J_{i, t} \\
\text { (Jones) }\end{array}$ & $\begin{array}{c}D A K_{i, t} \\
\text { (Kothari) }\end{array}$ \\
\hline$R M 1_{i, t}$ & - & $0.8313 * *$ & $0.7796 * * *$ & $0.1601 * * *$ & $0.1560 * * *$ & $0.1788 * * *$ \\
\hline$A \_D I S E X P_{i, t}$ & $0.8463 * * *$ & - & $0.2704 * * *$ & $0.2080 * * *$ & $0.2087 * * *$ & $0.0511 * *$ \\
\hline$A_{-} P R O D_{i, t}$ & $0.8073 * * *$ & $0.4520 * * *$ & - & $0.1139 * * *$ & $0.1497 * * *$ & $0.1260 * * *$ \\
\hline $\begin{array}{c}D A M J_{i, t} \\
\text { (M. Jones) }\end{array}$ & $0.1843 * * *$ & $0.1324 * * *$ & $0.1418 * * *$ & - & $0.9186 * * *$ & $0.6735 * * *$ \\
\hline $\begin{array}{c}D A J_{i, t} \\
\text { (Jones) }\end{array}$ & $0.1693 * * *$ & $0.1379 * * *$ & $0.1359 * * *$ & $0.8515 * * *$ & - & $0.5962 * * *$ \\
\hline $\begin{array}{c}D A K_{i, t} \\
\text { (Kothari) }\end{array}$ & $0.1489 * * *$ & $0.0564 * * *$ & $0.1920 * * *$ & $0.7888 * * *$ & $0.6964 * * *$ & - \\
\hline
\end{tabular}


Table 3: Portfolio Analysis of Leverage Levels and Changes and Accrual-based and Real Earnings Management. For the sample of suspect firm-years (as defined in Section 4.1), the Table reports medians of accrual-based and real earnings management measures for five, annually-rebalanced portfolios based on leverage ( $L e v_{i, t^{-}}$Panel A) and changes in leverage $\left(\Delta L e v_{i, t^{-}}\right.$Panel B). Portfolio 1 consists of the firms with the lowest TD/TA (or change in TD/TA) in every year, while Portfolio 5 consists of the firms with the highest TD/TA (or change in TD/TA). ( $A_{-} D I S E X P_{i, t}$ ) has been multiplied by negative one as discussed in Section 3.2. $\mathrm{A} \uparrow, \uparrow \dagger, \dagger+\dagger$ indicates that the portfolio median is statistically different from zero at the $10 \%, 5 \%$ and $1 \%$ significance level respectively. A $\ddagger$, $+\downarrow$ and $+\uparrow \dagger$ indicates that the Wilcoxon rank sum test statistic rejects the null hypothesis that the EM metrics of Portfolios 5 and 1 are from distributions with equal medians at the $10 \%$, $5 \%$ and $1 \%$ significance level respectively. z-values of the Wilcoxon rank sum test statistic appear in square brackets.

Panel A: Levels of Leverage $\left(\operatorname{Lev}_{i, t}=T D_{i, t} / T A_{i, t}\right)$

\begin{tabular}{c}
\hline Portfolios \\
Lev $_{i, t}$ \\
\hline 1-Lowest \\
2 \\
3 \\
4 \\
5-Highest \\
\hline
\end{tabular}

\begin{tabular}{ccc}
\hline \multicolumn{3}{c}{ Accrual-based Earnings Management } \\
\hline Jones & Modified Jones & Kothari \\
\hline $0.032^{\dagger \dagger \dagger}$ & $0.027^{\dagger \dagger \dagger}$ & -0.004 \\
$0.041^{\dagger \dagger \dagger}$ & $0.038^{\dagger \dagger \dagger}$ & $0.009^{\dagger \dagger \dagger}$ \\
$0.029^{\dagger \dagger \dagger}$ & $0.030^{\dagger \dagger \dagger}$ & $0.008^{\dagger \dagger \dagger}$ \\
$0.019^{\dagger \dagger \dagger}$ & $0.016^{\dagger \dagger \dagger}$ & -0.004 \\
$0.021^{\dagger \dagger \dagger}$ & $0.017^{\dagger \dagger \dagger}$ & $0.007^{\dagger \dagger \dagger}$
\end{tabular}

\begin{tabular}{ccc}
\hline \multicolumn{3}{c}{ Real Earnings Management } \\
\hline$A \_P R O D_{i, t}$ & $A \_D I S E X P_{i, t}$ & $R M 1_{i, t}$ \\
\hline$-0.078^{\dagger \dagger \dagger}$ & $-0.033^{\dagger \dagger \dagger}$ & $-0.089^{\dagger \dagger \dagger}$ \\
$-0.045^{\dagger \dagger \dagger}$ & 0.005 & $-0.029^{\dagger}$ \\
-0.005 & $0.031^{\dagger \dagger \dagger}$ & $0.066^{\dagger \dagger \dagger}$ \\
-0.003 & $0.021^{\dagger \dagger \dagger}$ & $0.037^{\dagger \dagger \dagger}$ \\
$0.012^{\dagger \dagger}$ & $0.029^{\dagger \dagger \dagger}$ & $0.059^{\dagger \dagger \dagger}$ \\
\hline & & \\
$0.090^{\dagger \dagger}$ & $0.062^{\dagger \dagger}$ & $0.148^{\dagger+\dagger}$ \\
{$[7.35]$} & {$[5.51]$} & {$[6.53]$}
\end{tabular}

Panel B: Changes in Leverage $\left(\Delta L e v_{i, t}=T D_{i, t} / T A_{i, t}-T D_{i, t-1} / T A_{i, t-1}\right)$

\begin{tabular}{c}
\hline Portfolios \\
$\Delta L e v_{i, t}$ \\
\hline 1-Lowest \\
2 \\
3 \\
4 \\
5-Highest
\end{tabular}

\begin{tabular}{ccc}
\hline \multicolumn{3}{c}{ Accrual-based Earnings Management } \\
\hline Jones & Modified Jones & Kothari \\
\hline $0.028^{\dagger \dagger \dagger}$ & $0.022^{\dagger \dagger \dagger}$ & -0.011 \\
$0.013^{\dagger \dagger \dagger}$ & $0.011^{\dagger \dagger \dagger}$ & -0.012 \\
$0.015^{\dagger \dagger \dagger}$ & $0.012^{\dagger \dagger \dagger}$ & -0.004 \\
$0.028^{\dagger \dagger \dagger}$ & $0.026^{\dagger \dagger \dagger}$ & $0.015^{\dagger \dagger \dagger}$ \\
$0.045^{\dagger \dagger \dagger}$ & $0.041^{\dagger \dagger \dagger}$ & $0.023^{\dagger \dagger \dagger}$
\end{tabular}

\begin{tabular}{ccc}
\hline \multicolumn{3}{c}{ Real Earnings Management } \\
\hline$A \_P R O D_{i, t}$ & A_DISEXP & $R M 1_{i, t}$ \\
\hline$-0.045^{\dagger \dagger \dagger}$ & $-0.012^{\dagger \dagger}$ & $-0.045^{\dagger \dagger}$ \\
$-0.032^{\dagger \dagger}$ & $0.038^{\dagger \dagger \dagger}$ & $0.046^{\dagger \dagger \dagger}$ \\
-0.020 & $0.012^{\dagger \dagger}$ & 0.018 \\
-0.002 & $0.033^{\dagger \dagger \dagger}$ & $0.046^{\dagger \dagger \dagger}$ \\
0.007 & 0.012 & $0.044^{\dagger \dagger}$ \\
$0.052^{\dagger+}$ & & \\
{$[3.14]$} & $0.024^{\dagger+}$ & $0.099^{+*}$ \\
& {$[2.50]$} & {$[2.92]$}
\end{tabular}


Table 4: Financial Leverage, Financial Health, and Accrual-based and Real Earnings Management. For the sample of suspect firm-years (as defined in Section 4.1), the Table reports medians of accrual-based and real earnings management measures for firms with Altman's $Z$ score $\left(A l t Z_{i, t}\right)$ values $<1.81$ ('Distressed firms') and Z Score values above or equal to 1.81 ('Healthy firms') grouped into one of five leverage ( Lev $\left._{i, t}\right)$ annually rebalanced portfolios. ( $\left.A_{-} D I S E X P_{i, t}\right)$ has been multiplied by negative one as discussed in Section 3.2. A $\dagger, \dagger \dagger, \dagger \dagger \dagger$ indicates that the portfolio median is statistically different from zero at the $10 \%, 5 \%$ and $1 \%$ significance level respectively. A $\$,+\dagger$ and $+\$+$ indicates that the Wilcoxon rank sum test statistic rejects the null hypothesis that the EM metrics of firms with an Altman's Z score below/above 1.81 are from distributions with equal medians at the $10 \%, 5 \%$ and $1 \%$ significance level respectively. p-values of the Wilcoxon rank sum test statistic appear in square brackets.

Levels of Leverage $\left(\operatorname{Lev}_{i, t}=T D_{i, t} / T A_{i, t}\right)$

\begin{tabular}{|c|c|c|c|c|c|c|c|c|}
\hline \multirow{4}{*}{$\begin{array}{c}\text { Portfolios } \\
\text { of } \\
L e v_{i, t}\end{array}$} & \multicolumn{3}{|c|}{ Accrual-based Earnings Management } & \multicolumn{5}{|c|}{ Real Earnings Management } \\
\hline & Jones & Modified Jones & Kothari & \multicolumn{3}{|c|}{$A \_D I S E X P_{i, t}$} & \multicolumn{2}{|c|}{$R M 1_{i, t}$} \\
\hline & Altman's $Z$ & Altman's $Z$ & Altman's $Z$ & Altman's $Z$ & \multicolumn{2}{|c|}{ Altman's $Z$} & \multicolumn{2}{|c|}{ Altman's $Z$} \\
\hline & Distressed $\quad$ Healthy & Distressed Healthy & Distressed Healthy & Distressed Healthy & Distressed & Healthy & Distressed & Healthy \\
\hline 1-Lowest & $0.0317^{\dagger \dagger \dagger}$ & $0.0257^{\dagger \dagger \dagger}$ & -0.0046 & $-0.0845^{\dagger \dagger \dagger}$ & -0.0484 & $-0.0371^{i \dagger \dagger}$ & 0.0012 & -0.0934 \\
\hline Diff. H - D & $0.0309[0.62]$ & $0.0255[0.70]$ & $-0.0152[0.30]$ & $-0.0844[0.20]$ & 0.0113 & {$[0.59]$} & -0.094 & {$[0.90]$} \\
\hline 2 & $0.1417^{\dagger \dagger} \quad 0.0355^{\dagger \dagger \dagger}$ & $0.1337^{\dagger \dagger} \quad 0.0366^{\dagger \dagger \dagger}$ & $0.1001^{\dagger \dagger} \quad 0.0065^{\dagger \dagger \dagger}$ & $-0.0468^{\dagger \dagger \dagger}$ & $-0.2345^{\dagger \dagger \dagger}$ & 0.0041 & 0.1690 & $-0.0418^{\dagger+\dagger}$ \\
\hline Diff. H - D & $-0.1061^{\text {ttt }}[0.00]$ & $-0.0970^{+*}[0.00]$ & $-0.0937^{\mathrm{tt}}[0.00]$ & $-0.4295^{\mathrm{tt}}[0.00]$ & $0.2385^{\sharp}$ & {$[0.00]$} & -0.210 & {$[0.19]$} \\
\hline 3 & $0.1037^{\dagger \dagger} \quad 0.0291^{\dagger \dagger}$ & $0.1523^{\dagger \dagger \dagger} \quad 0.0286^{\dagger \dagger \dagger}$ & $0.1102^{\dagger \dagger \dagger}$ & -0.0075 & -0.0080 & $0.0316^{\dagger \dagger \dagger}$ & 0.2634 & $0.0572^{\dagger \dagger \dagger}$ \\
\hline Diff. H - D & $-0.0746^{\dagger+}[0.00]$ & $-0.1237^{+*}[0.00]$ & $-0.1070^{\text {tt! }}[0.00]$ & $0.0019[0.57]$ & 0.0396 & {$[0.42]$} & -0.206 & {$[0.24]$} \\
\hline 4 & $0.0050 \quad 0.0190^{\dagger \dagger}$ & $0.0238 \quad 0.0147^{\dagger \dagger \dagger}$ & $0.0105 \quad-0.0056$ & $0.0528^{\dagger}$ & 0.0090 & $0.0297^{\dagger \dagger \dagger}$ & 0.0055 & $0.0520^{\dagger \dagger \dagger}$ \\
\hline Diff. H - D & $0.0140[0.87]$ & $-0.0092[0.61]$ & $-0.0161[0.31]$ & $-0.0622^{+}[0.03]$ & 0.0207 & {$[0.06]$} & 0.046 & {$[0.74]$} \\
\hline 5-Highest & $0.0284^{\dagger \dagger}$ & $0.0205^{\dagger \dagger}$ & $0.0154^{\dagger \dagger}$ & $0.0263^{\dagger \dagger}$ & 0.0207 & $0.0322^{\dagger \dagger}$ & $0.0672^{\dagger \dagger \dagger}$ & $0.0460^{\dagger+\dagger}$ \\
\hline Diff. H - D & $-0.0098[0.12]$ & $-0.0033[0.20]$ & $-0.0143^{\ddagger}[0.08]$ & $-0.0251[0.14]$ & 0.0115 & {$[0.23]$} & -0.021 & {$[0.37]$} \\
\hline $\begin{array}{c}\text { Difference } \\
\text { Port.5.- Port.1 }\end{array}$ & $\begin{array}{c}-0.0131^{\ddagger} \\
{[0.07]}\end{array}$ & $\begin{array}{c}-0.0085 \\
{[0.26]}\end{array}$ & $\begin{array}{l}0.0048 \\
{[0.77]}\end{array}$ & $\begin{array}{c}0.0856^{\dagger+} \\
{[0.00]}\end{array}$ & $\begin{array}{c}0.0692^{\text {\#t }} \\
{[0.00]}\end{array}$ & $\begin{array}{c}0.0693^{\text {tht }} \\
{[0.00]}\end{array}$ & $\begin{array}{l}0.0660 \\
{[0.17]}\end{array}$ & $\begin{array}{c}0.1394 \text { 林 } \\
{[0.00]}\end{array}$ \\
\hline
\end{tabular}


Table 5: Leverage Levels and EM: Regression Analysis. In Panel A, the Table reports estimation results of the following probit model, used as the first step of the Heckman (1979) procedure:

$$
\begin{aligned}
\operatorname{Pr}\left[\text { SUSPECT }_{i, t}=1\right. & =\Phi\left(\gamma_{0}+\gamma_{1} \text { HabBeat }_{i, t}+\gamma_{2} \text { AnalystFollow }_{i, t}+\gamma_{3} \text { Shares }_{i, t}+\gamma_{4} \text { MtoB }_{i, t-1}+\gamma_{5} \text { ROA }_{i, t}\right. \\
& \left.+\sum_{k} \gamma_{6, k} \text { YearIndicator }_{k, i, t}+e_{i, t}\right)=\Phi\left(\mathbf{z}_{i, t} \boldsymbol{\gamma}+e_{i, t}\right)
\end{aligned}
$$

The variable $\operatorname{SUSPECT} T_{i, t}$ is a dummy variable that equals 1 if firm $i$ in year $t$ is suspect of earnings management, and zero if firm $i$ in year $t$ is non-suspect. For the definitions of earnings management suspect and non-suspect firm-years, see the details in Section 4.1. Operators $\operatorname{Pr}[$.$] and$ $\Phi($.$) denote probability and the cumulative distribution function of the standard normal$ distribution respectively. All independent variables are as defined in Section 4.1. The marginal effect is calculated as the change in $\Phi\left(\mathbf{z}_{i, t} \widehat{\gamma}\right)$ when the variable in question in the vector of independent variables $\boldsymbol{z}_{i, t}$ changes by one, and all other variables are set at their mean values (all year indicators are set to zero in the marginal effects calculations). $\log L$ denotes the maximised $\log$-likelihood and LR $\chi^{2}$ stat. is the Likelihood Ratio Chi-Square test under the null hypothesis that at least one of the independent variables' coefficients is not equal to zero, and the test's p-value appears in square brackets. Pseudo $R^{2}$ is McFadden's measure of goodness of fit, computed as $1-\log L / \log L_{c}$, where $\log L_{c}$ denotes the (constrained) $\log$-likelihood of a model with an intercept only. Asterisks $*, * *$ and $* * *$ indicate coefficient statistical significance at the $10 \%, 5 \%$

\begin{tabular}{|c|c|c|c|c|}
\hline \multicolumn{5}{|c|}{ Panel A: Heckman (1979) first step probit model estimation results } \\
\hline & Pred. Sign & Coefficient & z-statistic & Marginal effect \\
\hline Intercept & & $-3.0470 * * *$ & -14.82 & \\
\hline HabBeat $_{i, t}$ & + & $0.1553 * * *$ & 12.53 & 0.0210 \\
\hline AnalystFollow $_{i, t}$ & + & $0.0890 * * *$ & 3.10 & 0.0153 \\
\hline Shares $_{i, t}$ & + & $0.1024 * * *$ & 5.22 & 0.0193 \\
\hline $\operatorname{MtoB}_{i, t-1}$ & + & -0.0014 & -0.98 & -0.0001 \\
\hline$R O A_{i, t}$ & & -0.0018 & -1.26 & -0.0003 \\
\hline Year Indicators & & Yes & & \\
\hline LR $\chi^{2}$ stat. & & $\begin{array}{c}\text { 406.48\#\#\# } \\
{[0.000]}\end{array}$ & Pseudo $R^{2}$ & 0.0416 \\
\hline No. Obs. & & 12,583 & $\log L$ & $-4,681.83$ \\
\hline
\end{tabular}
and $1 \%$ level respectively. 
In Panel B, the Table reports estimation results of the following recursive system of equations that constitute the second step of the Heckman (1979) procedure:

$$
\begin{aligned}
& R M_{i, t}=\alpha_{0}+\alpha_{1} \operatorname{Lev}_{i, t}+\sum_{k} \alpha_{2, k} \operatorname{Costs} \text { of } R M_{k, i, t}+\sum_{l} \alpha_{3, l} \operatorname{Costs} \text { of } A M_{l, i, t}+\sum_{m} \alpha_{4, m} \operatorname{Controls}_{m, i, t}+\varepsilon_{i, t} \\
& A M_{i, t}=\beta_{0}+\beta_{1} \text { Lev }_{i, t}+\sum_{k} \beta_{2, k} \operatorname{Costs} \text { of } R M_{k, i, t}+\sum_{l} \beta_{3, l} \text { Costs of } A M_{l, i, t}+\sum_{m} \beta_{4, m} \text { Controls }_{m, i, t}+\beta_{5} \text { UnexpectedRM } M_{i, t} \\
& +\beta_{6}\left(\text { UnexpectedRM }_{i, t} \times \text { Lev }_{i, t}\right)+\epsilon_{i, t}
\end{aligned}
$$

The dependent variables $R M_{i, t}$ and $A M_{i, t}$ are respectively the real earnings management and accrual-based earnings management metrics outlined in Section 3 (of the former only the comprehensive $R M 1_{i, t}$ and of the latter only the Modified Jones model are reported for brevity). All independent variables are as defined in Section 4.1. $\widehat{R M}_{i, t}$ is the predicted values from the first equation of the recursive system, while $I M R_{i, t}$ is the inverse of Mill's ratio (the non-selection hazard rate) from the first stage of the Heckman (1979) procedure, calculated as $\varphi\left(\mathbf{z}_{i, t} \widehat{\boldsymbol{\gamma}}\right) / \Phi\left(\mathbf{z}_{i, t} \widehat{\boldsymbol{\gamma}}\right)$, with $\varphi($.$) the density and \Phi($.$) the cumulative density function of the standard$ normal distribution. z-statistic values are reported in parentheses, and asterisks $*$, ** and $* * *$ indicate statistical significance at the $10 \%, 5 \%$ and $1 \%$ level respectively. The Wald $\chi^{2}$ statistic is a Wald test that all coefficients in the regression model (except the constant) are all equal to zero (and its $\mathrm{p}$-value is reported in square brackets). The Wald $\chi^{2}$ statistic for $(H 2 a): \beta_{5}+\beta_{6} \times \widetilde{L e v} \leq 0$ is a one-sided Wald test that the coefficient of Unexpected $R M_{i, t}$, evaluated at the median leverage $\widetilde{L e v}$, is non-positive. Our (H2) hypothesis predicts that this null should be rejected. (p-values of Wald tests are reported in square brackets). LogL denotes the maximised log-likelihood and Pseudo $R^{2}$ is McFadden's measure of goodness of fit, computed as

\begin{tabular}{|c|c|c|c|c|}
\hline & $R M$ & $n\left(R M 1_{i, t}\right)$ & $A M$ equ & MJONES $\left.S_{i, t}\right)$ \\
\hline & Pred. Sign & Coefficient & Pred. Sign & Coefficient \\
\hline Intercept & & $\begin{array}{c}-1.9489 * * * \\
(-7.24)\end{array}$ & & $\begin{array}{c}-0.0207 \\
(-0.02)\end{array}$ \\
\hline $\operatorname{Lev}_{i, t}$ & + & $\begin{array}{c}0.1636^{*} \\
(1.90)\end{array}$ & - & $\begin{array}{c}-0.0480 \\
(-0.24)\end{array}$ \\
\hline Unexpected $R M_{i, t}$ & & & - & $\begin{array}{c}-0.1931 * * * \\
(-5.50)\end{array}$ \\
\hline Lev $_{i, t} \times$ Unexpected $R M_{i, t}$ & & & + & $\begin{array}{c}0.4889 * * * \\
(4.24)\end{array}$ \\
\hline Costs Associated with Real & ies Manipu & & & \\
\hline MarketShare $_{i, t-1}$ & + & $\begin{array}{c}-0.1262 \\
(-1.28)\end{array}$ & & $\begin{array}{c}0.1602 \\
(1.20)\end{array}$ \\
\hline ZScore $_{i, t-1}$ & + & $\begin{array}{c}-0.0136 \\
(-1.41)\end{array}$ & & $\begin{array}{c}-0.0017 \\
(-0.11)\end{array}$ \\
\hline$M T R_{i, t}$ & - & $\begin{array}{c}0.1179 \\
(1.16)\end{array}$ & & $\begin{array}{c}0.2075^{*} \\
(1.65)\end{array}$ \\
\hline Costs Associated with Acci & sed Earnin & agement & & \\
\hline$B I G_{i, t}$ & & $\begin{array}{c}-0.0640 \\
(-1.16)\end{array}$ & - & $\begin{array}{c}0.0045 \\
(0.06)\end{array}$ \\
\hline$N O A_{i, t-1}$ & & $\begin{array}{c}-0.0752 * * \\
(-2.56)\end{array}$ & - & $\begin{array}{c}-0.1379 * * \\
(-2.37)\end{array}$ \\
\hline Cycle $_{i, t-1}$ & & $\begin{array}{c}-0.0004 * * * \\
(-3.59)\end{array}$ & + & $\begin{array}{c}-0.0001 \\
(-0.57)\end{array}$ \\
\hline
\end{tabular}
$1-\log L / \log L_{c}$, where $\log L_{c}$ denotes the (constrained) $\log$-likelihood of a model with an intercept only. 


\section{Control Variables}

$R O A_{i, t}$

$-0.2378 * *$

$(-2.02)$

$0.0830 * * *$

(4.22)

Assets $_{i, t}$

$0.0225 * * *$

$(-3.96)$

$\operatorname{MtoB}_{i, t}$

$0.0953 * *$

INVRECT $A_{i, t}$

$\widehat{R M}_{i, t}$

$-0.7964$

$(-1.35)$

$0.7226 * * *$

0.0358

(17.19)

(0.47)

Wald $\chi^{2}$ stat.

77.88\#\#\#

[0.000]

Wald $\chi^{2}$ stat. for

101.86\#\#\#

[0.000]

10.48\#\#\#

$(H 2): \beta_{5}+\beta_{6} \times \widetilde{\operatorname{Lev}} \leq 0$

[0.006]

No. Obs.

1,648

1,555

Pseudo $R^{2} / \log L$

$0.2656 /-6,062.47$

$0.3993 /-5,925.90$

Variance-Inflation-Factors (VIFs)

$L e v_{i, t}$

1.4237

1.7646

$I M R_{i, t}$

1.2171

1.8734 
Table 6: Leverage Levels and EM: Regression Analysis. The Table summarises the estimation results of the recursive system of equations in (2) that constitute the second step of the Heckman (1979) procedure. This is identical to Table 4, only the continuous variable $L e v_{i, t}$ is now replaced by the sum of five multiplicative terms Lev $_{i, t} \times \mathbf{1}_{\text {Quantile }=q}, q=\{1,2,3,4,5\}$. The indicator function $\mathbf{1}_{\text {Quantile= } q}$ takes the value of one if the leverage of firm $i$ in year $t$ belongs to the $q^{\text {th }}$ leverage quantile over the sample period, and zero otherwise. The Wald $\chi^{2}$ statistic for $(H 2 a): \beta_{5}+\beta_{6} \times \widetilde{L e v}_{q=5} \leq 0$ is an one-sided Wald test that the coefficient of Unexpected $R M_{i, t}$, evaluated at the median leverage of high-levered sample firms, $\widetilde{L e v_{q=5}}$, is non-positive. Our (H2) hypothesis predicts that this null should be rejected (the p-value of the Wald test is reported in square brackets). All other variable definitions and reported statistics are as in Table 4, and asterisks *, ** and $* * *$ indicate statistical significance at the $10 \%, 5 \%$ and $1 \%$ level respectively.

\begin{tabular}{|c|c|c|c|c|}
\hline & \multicolumn{2}{|c|}{$R M$ equation $\left(R M 1_{i, t}\right)$} & \multicolumn{2}{|c|}{$A M$ equation $\left(M J O N E S_{i, t}\right)$} \\
\hline & Pred. Sign & Coefficient & Pred. Sign & Coefficient \\
\hline Intercept & & $\begin{array}{l}3.0131 * * * \\
(7.22)\end{array}$ & & $\begin{array}{l}-0.2192 \\
(-0.19)\end{array}$ \\
\hline Lev $_{i, t} \times \mathbf{1}_{\text {Quantile }=1}($ Lowest $)$ & + & $\begin{array}{c}1.0800 \\
(0.81)\end{array}$ & & $\begin{array}{l}1.8381 \\
(1.02)\end{array}$ \\
\hline $\operatorname{Lev}_{i, t} \times \mathbf{1}_{\text {Quantile }=2}$ & + & $\begin{array}{l}1.1398^{* *} \\
(2.08)\end{array}$ & & $\begin{array}{l}1.2360 \\
(1.56)\end{array}$ \\
\hline Lev $_{i, t} \times \mathbf{1}_{\text {Quantile }=3}$ & + & $\begin{array}{c}0.4582 \\
(1.38)\end{array}$ & & $\begin{array}{c}0.5024 \\
(1.11)\end{array}$ \\
\hline Lev $_{i, t} \times \mathbf{1}_{\text {Quantile }}=4$ & + & $\begin{array}{l}0.5434 * * \\
(2.28)\end{array}$ & & $\begin{array}{c}0.1325 \\
(0.37)\end{array}$ \\
\hline Lev $_{i, t} \times \mathbf{1}_{\text {Quantile }=5}$ (Highest $)$ & + & $\begin{array}{l}0.6337 * * * \\
\quad(3.13)\end{array}$ & & $\begin{array}{c}0.0663 \\
(0.29)\end{array}$ \\
\hline Unexpected $R M_{i, t}$ & & & - & $\begin{array}{l}-0.1005 * * \\
(-2.45)\end{array}$ \\
\hline $\begin{array}{l}\text { Lev }_{i, t} \times \text { Unexp. } R M_{i, t} \times \mathbf{1}_{\text {Quantile }}=1 \\
\text { (Lowest) }\end{array}$ & & & & $\begin{array}{c}-0.8111 \\
(-0.57)\end{array}$ \\
\hline Lev $_{i, t} \times$ Unexp. $R M_{i, t} \times \mathbf{1}_{\text {Quantile }=2}$ & & & & $\begin{array}{c}-0.3817 \\
(-0.66)\end{array}$ \\
\hline Lev $_{i, t} \times$ Unexp. $R M_{i, t} \times \mathbf{1}_{\text {Quantile }=3}$ & & & & $\begin{array}{l}0.0471 \\
(0.13)\end{array}$ \\
\hline Lev $_{i, t} \times$ Unexp. $R M_{i, t} \times \mathbf{1}_{\text {Quantile }}=4$ & & & & $\begin{array}{c}0.3344 \\
(1.24)\end{array}$ \\
\hline $\begin{array}{l}\text { Lev }_{i, t} \times \text { Unexp. } R M_{i, t} \times \mathbf{1}_{\text {Quantile }}=5 \\
(\text { Highest })\end{array}$ & & & & $\begin{array}{l}0.4691 * * * \\
\quad(3.54)\end{array}$ \\
\hline \multicolumn{5}{|c|}{ Costs Associated with Real Activities Manipulation } \\
\hline MarketShare $_{i, t-1}$ & + & $\begin{array}{c}0.2618 \\
(1.54)\end{array}$ & & $\begin{array}{l}0.1415 \\
(1.06)\end{array}$ \\
\hline ZScore $_{i, t-1}$ & + & $\begin{array}{c}0.0235 \\
(1.58)\end{array}$ & & $\begin{array}{c}0.0014 \\
(0.09)\end{array}$ \\
\hline$M T R_{i, t}$ & - & $\begin{array}{c}0.0950 \\
(0.55)\end{array}$ & & $\begin{array}{l}0.1920 \\
(1.50)\end{array}$ \\
\hline \multicolumn{5}{|c|}{ Costs Associated with Accrual-Based Earnings Management } \\
\hline$B I G_{i, t}$ & & $\begin{array}{c}-0.0119 \\
(-0.13)\end{array}$ & - & $\begin{array}{c}0.0077 \\
(0.11)\end{array}$ \\
\hline$N O A_{i, t-1}$ & & $\begin{array}{l}-0.0618 \\
(-1.23)\end{array}$ & - & $\begin{array}{c}-0.1382 * * \\
(-2.35)\end{array}$ \\
\hline Cycle $_{i, t-1}$ & & $\begin{array}{c}-0.0003^{*} \\
(-1.95)\end{array}$ & + & $\begin{array}{c}-0.0002 \\
(-0.72)\end{array}$ \\
\hline $\begin{array}{l}\text { Control Variables } \\
R O A_{i, t}\end{array}$ & & $-0.4946^{* *}$ & & $-0.0234 * * *$ \\
\hline
\end{tabular}


$\widehat{R M}_{i, t}$

$I M R_{i, t}$

Wald $\chi^{2}$ stat.

Wald $\chi^{2}$ stat. for

$(H 2): \beta_{5}+\beta_{6} \times \widetilde{\operatorname{Lev}}_{q=5} \leq 0$

No. Obs.

Pseudo $R^{2} / \log L$

Variance-Inflation-Factors (VIFs)

$L e v_{i, t}$

$I M R_{i, t}$
$(-2.24)$

$-0.0954 * * *$

$(-2.90)$

$-0.0531 * * *$

$(-5.42)$

$0.1935 * *$

(2.22)

$(-3.54)$

$-0.0631$

$(-1.27)$

$-0.0121$

$(-0.76)$

$-0.8176$

$(-1.38)$

0.0416

(0.56)

$(-18.82)$

$81.37 * * *$

[0.000]

$106.64 * * *$

[0.000]

9.50\#\#

[0.010]

1,648

1,555

$0.2629 /-6,056.16$

$0.3996 /-6,711.52$

1.3565

1.0621

1.3258

1.2219 
Table 7: Different Changes in Leverage and EM: Regression Analysis. The Table summarises the estimation results of the recursive system of equations in (2) that constitute the second step of the Heckman (1979) procedure, only now the continuous variable $\Delta L e v_{i, t}$ is replaced by the sum of five multiplicative terms $\Delta L e v_{i, t} \times \mathbf{1}_{\Delta \text { Quantile }=q}, q=\{1,2,3,4,5\}$. The indicator function $\mathbf{1}_{\Delta Q \text { uantile }=q}$ takes the value of one if the leverage annual change $\Delta L e v_{i, t}$ of firm $i$ in year $t$ belongs to the $q^{\text {th }}$ leverage change quantile over the sample period, and zero otherwise. The Wald $\chi^{2}$ statistic for $(H 2): \beta_{5}+\beta_{6} \times \widetilde{\Delta L e v}_{q=5} \leq 0$ is an one-sided Wald test that the coefficient of Unexpected $R M_{i, t}$, evaluated at the median leverage change of sample firms in the $\mathbf{1}_{\Delta Q \text { uantile=5 }}$ quintile, $\widehat{\triangle L e v}_{q=5}$, is non-positive. Our (H2) hypothesis predicts that this null should be rejected (the p-value of the Wald test is reported in square brackets).All variable definitions and reported statistics are as in Table 4 , and asterisks $*, * *$ and $* * *$ indicate statistical significance at the $10 \%, 5 \%$ and $1 \%$ level respectively.

\begin{tabular}{|c|c|c|c|c|}
\hline & \multicolumn{2}{|c|}{$R M$ equation $\left(R M 1_{t}\right)$} & \multicolumn{2}{|c|}{$A M$ equation $\left(M J O N E S_{t}\right)$} \\
\hline & Pred. Sign & Coefficient & Pred. Sign & Coefficient \\
\hline Intercept & & $\begin{array}{l}2.7185^{* * * *} \\
(6.74)\end{array}$ & & $\begin{array}{l}3.0570 * * * \\
(3.29)\end{array}$ \\
\hline$\Delta L e v_{i, t} \times \mathbf{1}_{\Delta Q u a n t i l e=1}($ Lowest $)$ & + & $\begin{array}{r}-0.2141 \\
(-0.49)\end{array}$ & & $\begin{array}{r}-0.3057 \\
(-0.57)\end{array}$ \\
\hline$\Delta L e v_{i, t} \times \mathbf{1}_{\Delta Q \text { uantile }=2}$ & + & $\begin{array}{c}-1.4312 \\
(-1.28)\end{array}$ & & $\begin{array}{c}-0.5023 \\
(-0.28)\end{array}$ \\
\hline$\Delta L e v_{i, t} \times \mathbf{1}_{\Delta Q u a n t i l e=3}$ & + & $\begin{array}{l}-3.7338 \\
(-0.87)\end{array}$ & & $\begin{array}{c}-5.2482 \\
(-0.79)\end{array}$ \\
\hline$\Delta L e v_{i, t} \times \mathbf{1}_{\Delta Q u a n t i l e=4}$ & + & $\begin{array}{r}0.0326 \\
(0.09)\end{array}$ & & $\begin{array}{c}-0.4838 \\
(-0.26)\end{array}$ \\
\hline$\Delta$ Lev $_{i, t} \times \mathbf{1}_{\Delta \text { Quantile }=5}($ Highest $)$ & + & $\begin{array}{l}2.5598 * * \\
(1.97)\end{array}$ & & $\begin{array}{c}-1.5258 * * \\
(-2.52)\end{array}$ \\
\hline Unexpected $R M_{i, t}$ & & & & $\begin{array}{c}-0.08483 * \\
(-1.82)\end{array}$ \\
\hline $\begin{array}{l}\Delta \text { Lev }_{i, t} \times \text { Unexp. } R M_{i, t} \times \mathbf{1}_{\Delta Q \text { uantile }}=1 \\
(\text { Lowest })\end{array}$ & & & & $\begin{array}{r}0.1159 \\
(0.32)\end{array}$ \\
\hline$\Delta L e v_{i, t} \times$ Unexp. $R M_{i, t} \times \mathbf{1}_{\Delta Q \text { uantile }=2}$ & & & & $\begin{array}{l}1.1708 \\
(0.85)\end{array}$ \\
\hline$\Delta L e v_{i, t} \times$ Unexp. $R M_{i, t} \times \mathbf{1}_{\Delta Q \text { uantile }=3}$ & & & & $\begin{array}{l}5.5532 \\
(1.05)\end{array}$ \\
\hline$\Delta L e v_{i, t} \times$ Unexp. $R M_{i, t} \times \mathbf{1}_{\Delta Q \text { uantile }=4}$ & & & & $\begin{array}{c}0.1908 \\
(0.13)\end{array}$ \\
\hline $\begin{array}{l}\Delta \text { Lev }_{i, t} \times \text { Unexp. } R M_{i, t} \times \mathbf{1}_{\Delta Q \text { uantile }}=5 \\
(\text { Highest })\end{array}$ & & & & $\begin{array}{c}0.8504^{*} \\
(1.68)\end{array}$ \\
\hline \multicolumn{5}{|c|}{ Costs Associated with Real Activities Manipulation } \\
\hline MarketShare $_{i, t-1}$ & + & $\begin{array}{c}0.2885^{*} \\
(1.70)\end{array}$ & & $\begin{array}{l}0.3743 * * * \\
\quad(2.99)\end{array}$ \\
\hline$Z$ core $_{i, t-1}$ & + & $\begin{array}{l}-0.0013 \\
(-0.09)\end{array}$ & & $\begin{array}{c}0.0036 \\
(0.24)\end{array}$ \\
\hline$M T R_{i, t}$ & - & $\begin{array}{l}0.1119 \\
(0.65)\end{array}$ & & $\begin{array}{l}0.0995 \\
(0.79)\end{array}$ \\
\hline \multicolumn{5}{|c|}{ Costs Associated with Accrual-Based Earnings Management } \\
\hline$B I G_{i, t}$ & & $\begin{array}{c}-0.0248 \\
(-0.26)\end{array}$ & - & $\begin{array}{c}0.0938 \\
(1.32)\end{array}$ \\
\hline$N O A_{i, t-1}$ & & $\begin{array}{l}-0.0635 \\
(-1.26)\end{array}$ & - & $\begin{array}{l}-00153 \\
(-0.31)\end{array}$ \\
\hline Cycle $_{i, t-1}$ & & $\begin{array}{c}-0.0004 * * \\
(-2.39)\end{array}$ & + & $\begin{array}{c}0.0005^{* * *} \\
(2.31)\end{array}$ \\
\hline
\end{tabular}

\section{Control Variables}


$R O A_{i, t}$

Assets $_{i, t}$

Mto $_{i, t}$

INVRECTA $A_{i, t}$

$\widehat{R M}_{i, t}$

$I M R_{i, t}$

Wald $\chi^{2}$ stat.

Wald $\chi^{2}$ stat. for

$(H 2): \beta_{5}+\beta_{6} \times \widetilde{\Delta L e v}_{q=5} \leq 0$

No. Obs.

Pseudo $R^{2} / \operatorname{Logl}$

Variance-Inflation-Factors (VIFs)

$\Delta \operatorname{Lev}_{i, t}$

$I M R_{i, t}$
$-0.5855^{* * * *}$

$(-2.63)$

$-0.0632 * *$

$(-2.00)$

$-0.0555 * * *$

$(-5.74)$

$0.2342 * * *$

(2.66)

$-1.2476 * * *$

$(-17.59)$

$75.97 * * *$

[0.000]

1,626

$0.2698 /-6,902.93$

1.0051

1.3548
$-0.0175^{* *}$

$(-2.34)$

$-0.1888 * * *$

$(-4.34)$

$0.0263 * *$

(2.03)

$0.9195 * *$

(2.06)

0.0247

(0.30)

$80.37 * * *$

[0.000]

1.30

[0.255]

1,540

$0.4026 /-5,893.54$

1.1567

1.4354 
Table 8: Leverage Levels, EM, and Subsequent Stock Market Performance for Suspect Firms. Each year we construct 9 portfolios for observations falling into the bottom $30 \%$, middle $40 \%$ or top $30 \%$ of total suspect firm-year observations based on (a) suspect firms' leverage Lev $_{i, t}$ and (b) suspect firms' earnings management (real and accrual-based) metrics, $R M_{i, t}$ and $A M_{i, t}$. For each portfolio every year $t$, we record its equally-weighted median buy-and-hold abnormal return (BHAR) starting April $t+1$ for the next 3,12 and 24 months in Panels A, B and C of the Table, respectively. We calculate BHARs as in Barber and Lyon (1997), where each suspect firm is matched each sample year with a control firm of similar size and book-to-market ratio, and the control firm's buy-and-hold return acts as the benchmark return in equation (3) of the text. $\mathrm{A}{ }^{\dagger},{ }^{\dagger},{ }^{\dagger \dagger}$ indicates that the portfolio median is statistically different from zero at the $10 \%, 5 \%$ and $1 \%$ significance level respectively. In rows/columns entitled $H_{0}$ : Equal Medians we report portfolio differences and z-values (in square brackets) under the null hypothesis that the medians of the indicated portfolios are equal. An \#, \#\#, \#\#\# indicates that the null is rejected at the $10 \%, 5 \%$ and $1 \%$ significance level respectively

Panel A: 3-month Portfolio BHARs

\begin{tabular}{|c|c|c|c|c|c|c|}
\hline \multicolumn{2}{|c|}{ 3-month Portfolio BHARs } & \multicolumn{3}{|c|}{ Portfolios of $L e v_{i, t}$ (Leverage level) } & \multirow{2}{*}{\multicolumn{2}{|c|}{$\begin{array}{l}H_{0}: \text { Equal Medians } \\
\text { Portfolios } 3 \text { and } 1\end{array}$}} \\
\hline & & \multirow{2}{*}{$\begin{array}{c}\text { Bottom } 30 \% \\
0.023^{\ddagger, a}\end{array}$} & \multirow{2}{*}{$\begin{array}{c}\text { Mid } 40 \% \\
0.043\end{array}$} & \multirow{2}{*}{$\frac{\text { Top } 30 \%}{0.078^{+\%}}$} & & \\
\hline Portfolios & Bottom $30 \%$ & & & & 0.055 & [1.04] \\
\hline \multirow{2}{*}{$\begin{array}{l}\text { of } D A M J_{i, t} \\
\text { (M. Jones) }\end{array}$} & Mid $40 \%$ & 0.001 & $0.046^{\ddagger}$ & $0.030^{\ddagger}$ & 0.030 & {$[0.86]$} \\
\hline & Top $30 \%$ & $-0.080^{\sharp 1}$ & -0.025 & $-0.039^{\sharp, \mathrm{b}}$ & 0.040 & {$[0.36]$} \\
\hline \multicolumn{2}{|c|}{$\begin{array}{l}H_{0}: \text { Equal Medians } \\
\text { Portfolios } 3 \text { and } 1\end{array}$} & $\begin{array}{c}-0.103 \# \# \# \\
{[-2.91]}\end{array}$ & $\begin{array}{c}-0.068 \# \\
{[-1.81]}\end{array}$ & $\begin{array}{c}-0.117 \# \# \# \\
{[-3.37]}\end{array}$ & \multicolumn{2}{|c|}{$\begin{array}{c}H_{0}: \text { Equal Medians } \\
\text { Portfolios b and a } \\
-0.063 \# \# \\
{[-2.56]}\end{array}$} \\
\hline \multirow{2}{*}{\multicolumn{2}{|c|}{ 3-month Portfolio BHARs }} & \multicolumn{3}{|c|}{ Portfolios of $\operatorname{Lev}_{i, t}$ (Leverage level) } & \multirow{2}{*}{\multicolumn{2}{|c|}{$\begin{array}{c}H_{0}: \text { Equal Medians } \\
\text { Portfolios } 3 \text { and } 1\end{array}$}} \\
\hline & & Bottom $30 \%$ & Mid $40 \%$ & Top $30 \%$ & & \\
\hline \multirow{3}{*}{$\begin{array}{l}\text { Portfolios } \\
\text { of } R M_{i, t}\end{array}$} & Bottom $30 \%$ & $0.025^{\mathrm{a}}$ & 0.024 & 0.047 & 0.022 & {$[-0.09]$} \\
\hline & Mid $40 \%$ & -0.022 & 0.013 & -0.010 & 0.012 & [0.83] \\
\hline & Top $30 \%$ & 0.000 & 0.003 & $0.016^{\mathrm{b}}$ & 0.017 & {$[0.95]$} \\
\hline \multicolumn{2}{|c|}{$\begin{array}{c}H_{0}: \text { Equal Medians } \\
\text { Portfolios } 3 \text { and } 1\end{array}$} & $\begin{array}{l}-0.025 \\
{[-1.12]}\end{array}$ & $\begin{array}{l}-0.021 \\
{[-0.20]}\end{array}$ & $\begin{array}{l}-0.031 \\
{[-0.02]}\end{array}$ & \multicolumn{2}{|c|}{$\begin{array}{c}H_{0} \text { : Equal Medians } \\
\text { Portfolios b and a } \\
-0.008 \\
{[-0.11]}\end{array}$} \\
\hline
\end{tabular}


Panel B: 12-month Portfolio BHARs

\begin{tabular}{|c|c|c|c|c|c|c|}
\hline \multirow{2}{*}{\multicolumn{2}{|c|}{ 12-month Portfolio BHARs }} & \multicolumn{3}{|c|}{ Portfolios of $L e v_{i, t}$ (Leverage level) } & \multirow{2}{*}{\multicolumn{2}{|c|}{$\begin{array}{l}H_{0}: \text { Equal Medians } \\
\text { Portfolios } 3 \text { and } 1\end{array}$}} \\
\hline & & \multirow{2}{*}{$\frac{\text { Bottom } 30 \%}{0.080^{\mathrm{a}}}$} & \multirow{2}{*}{$\begin{array}{c}\text { Mid } 40 \% \\
-0.037\end{array}$} & \multirow{2}{*}{$\begin{array}{c}\text { Top 30\% } \\
-0.026\end{array}$} & & \\
\hline Portfolios & Bottom $30 \%$ & & & & -0.107 & {$[-0.93]$} \\
\hline \multirow{2}{*}{$\begin{array}{l}\text { of } D A M J_{i, t} \\
\text { (M. Jones) }\end{array}$} & Mid $40 \%$ & 0.056 & $0.152^{\ddagger}$ & 0.047 & -0.009 & {$[-0.28]$} \\
\hline & Top $30 \%$ & -0.024 & -0.046 & $-0.047^{\mathrm{b}}$ & -0.022 & {$[-0.00]$} \\
\hline \multicolumn{2}{|c|}{$\begin{array}{c}H_{0} \text { : Equal Medians } \\
\text { Portfolios } 3 \text { and } 1\end{array}$} & $\begin{array}{l}-0.105 \\
{[-1.49]}\end{array}$ & $\begin{array}{l}-0.010 \\
{[0.40]}\end{array}$ & $\begin{array}{l}-0.021 \\
{[-0.62]}\end{array}$ & \multicolumn{2}{|c|}{$\begin{array}{c}H_{0}: \text { Equal Medians } \\
\text { Portfolios b and a } \\
-0.127 \\
{[-1.53]}\end{array}$} \\
\hline \multirow{2}{*}{\multicolumn{2}{|c|}{ 12-month Portfolio BHARs }} & \multicolumn{3}{|c|}{ Portfolios of $L e v_{i, t}$ (Leverage level) } & \multirow{2}{*}{\multicolumn{2}{|c|}{$\begin{array}{l}H_{0}: \text { Equal Medians } \\
\text { Portfolios } 3 \text { and } 1\end{array}$}} \\
\hline & & Bottom $30 \%$ & Mid $40 \%$ & Top $30 \%$ & & \\
\hline \multirow{3}{*}{$\begin{array}{l}\text { Portfolios } \\
\text { of } R M_{i, t}\end{array}$} & Bottom $30 \%$ & $0.025^{\mathrm{a}}$ & 0.060 & 0.099 & 0.074 & [0.50] \\
\hline & Mid $40 \%$ & 0.000 & -0.001 & 0.057 & 0.056 & {$[0.88]$} \\
\hline & Top 30\% & $0.113^{\ddagger}$ & $0.126^{\ddagger}$ & $0.035^{\mathrm{b}}$ & -0.077 & {$[-0.98]$} \\
\hline \multicolumn{2}{|c|}{$\begin{array}{c}H_{0}: \text { Equal Medians } \\
\text { Portfolios } 3 \text { and } 1\end{array}$} & $\begin{array}{l}0.088 \\
{[1.13]}\end{array}$ & $\begin{array}{l}0.065 \\
{[1.23]}\end{array}$ & $\begin{array}{l}-0.064 \\
{[-0.26]}\end{array}$ & \multicolumn{2}{|c|}{$\begin{array}{c}H_{0}: \text { Equal Medians } \\
\text { Portfolios } \mathrm{b} \text { and a } \\
0.010 \\
{[0.21]}\end{array}$} \\
\hline
\end{tabular}

Panel C: 24-month Portfolio BHARs

\begin{tabular}{|c|c|c|c|c|c|c|}
\hline \multirow{2}{*}{\multicolumn{2}{|c|}{ 24-month Portfolio BHARs }} & \multicolumn{3}{|c|}{ Portfolios of $L e v_{i, t}$ (Leverage level) } & \multirow{2}{*}{\multicolumn{2}{|c|}{$\begin{array}{l}H_{0} \text { : Equal Medians } \\
\text { Portfolios } 3 \text { and } 1\end{array}$}} \\
\hline & & \multirow{2}{*}{$\frac{\text { Bottom } 30 \%}{0.138^{\mathrm{a}}}$} & \multirow{2}{*}{$\frac{\text { Mid } 40 \%}{-0.096}$} & \multirow{2}{*}{$\begin{array}{c}\text { Top } 30 \% \\
0.124\end{array}$} & & \\
\hline Portfolios & Bottom $30 \%$ & & & & -0.014 & {$[-0.70]$} \\
\hline \multirow{2}{*}{$\begin{array}{l}\text { of } D A M J_{i, t} \\
\text { (M. Jones) }\end{array}$} & Mid $40 \%$ & $0.213^{\mathrm{fta}}$ & $0.188^{*}$ & 0.000 & $-0.213 \# \#$ & {$[-2.25]$} \\
\hline & Top 30\% & -0.006 & 0.028 & $-0.074^{\mathrm{b}}$ & -0.067 & {$[0.22]$} \\
\hline \multicolumn{2}{|c|}{$\begin{array}{l}H_{0}: \text { Equal Medians } \\
\text { Portfolios } 3 \text { and } 1\end{array}$} & $\begin{array}{l}-0.144 \\
{[-1.55]}\end{array}$ & $\begin{array}{l}0.124 \\
{[1.25]}\end{array}$ & $\begin{array}{l}-0.197 \\
{[-0.63]}\end{array}$ & \multicolumn{2}{|c|}{$\begin{array}{c}H_{0}: \text { Equal Medians } \\
\text { Portfolios b and a } \\
-0.211 \\
{[-1.28]} \\
\end{array}$} \\
\hline \multirow{2}{*}{\multicolumn{2}{|c|}{ 24-month Portfolio BHARs }} & \multicolumn{3}{|c|}{ Portfolios of $L e v_{i, t}$ (Leverage level) } & \multirow{2}{*}{\multicolumn{2}{|c|}{$\begin{array}{l}H_{0}: \text { Equal Medians } \\
\text { Portfolios } 3 \text { and } 1\end{array}$}} \\
\hline & & Bottom $30 \%$ & Mid $40 \%$ & Top $30 \%$ & & \\
\hline \multirow{3}{*}{$\begin{array}{l}\text { Portfolios } \\
\text { of } R M_{i, t}\end{array}$} & Bottom $30 \%$ & $-0.001^{\mathrm{a}}$ & -0.003 & 0.105 & 0.106 & {$[0.17]$} \\
\hline & Mid $40 \%$ & 0.043 & 0.081 & -0.035 & -0.079 & {$[-0.81]$} \\
\hline & Top $30 \%$ & $0.135^{*}$ & 0.122 & $0.111^{\mathrm{b}}$ & -0.024 & {$[-0.56]$} \\
\hline \multicolumn{2}{|c|}{$\begin{array}{c}H_{0} \text { : Equal Medians } \\
\text { Portfolios } 3 \text { and } 1\end{array}$} & $\begin{array}{l}0.136 \\
{[0.99]}\end{array}$ & $\begin{array}{l}0.125 \\
{[0.60]}\end{array}$ & $\begin{array}{l}0.006 \\
{[0.24]}\end{array}$ & \multicolumn{2}{|c|}{$\begin{array}{c}H_{0}: \text { Equal Medians } \\
\text { Portfolios b and a } \\
0.112 \\
{[0.38]}\end{array}$} \\
\hline
\end{tabular}


Table 9: Leverage Changes, EM, and Subsequent Stock Market Performance for Suspect Firms. Each year we construct 9 portfolios for observations falling into the bottom 30\%, middle $40 \%$ or top $30 \%$ of total suspect firm-year observations based on (a) suspect firms' change in leverage $\Delta L e v_{i, t}$ and (b) suspect firms' earnings management (real and accrual-based) metrics, $R M_{i, t}$ and $A M_{i, t}$. For each portfolio every year $t$, we record its equally-weighted median buy-and-hold abnormal return $(B H A R)$ starting April $t+1$ for the next 3,12 and 24 months in Panels A, B and C of the Table, respectively. We calculate BHARs as in Barber and Lyon (1997), where each suspect firm is matched each sample year with a control firm of similar size and book-to-market ratio, and the control firm's buy-and-hold return acts as the benchmark return in equation (3) of the text. $\mathrm{A}^{\dagger},{ }^{\dagger \dagger},{ }^{\dagger \dagger}$ indicates that the portfolio median is statistically different from zero at the $10 \%, 5 \%$ and $1 \%$ significance level respectively. In rows/columns entitled $H_{0}$ : Equal Medians we report portfolio differences and z-values (in square brackets) under the null hypothesis that the medians of the indicated portfolios are equal. An \#, \#\#, \#\#\# indicates that the null is rejected at the $10 \%, 5 \%$ and $1 \%$ significance level respectively

Panel A: 3-month Portfolio BHARs

\begin{tabular}{|c|c|c|c|c|c|c|}
\hline \multirow{2}{*}{\multicolumn{2}{|c|}{ 3-month Portfolio BHARs }} & \multicolumn{3}{|c|}{ Portfolios of $\Delta L e v_{i, t}$ (Leverage changes) } & \multirow{2}{*}{\multicolumn{2}{|c|}{$\begin{array}{l}H_{0} \text { : Equal Medians } \\
\text { Portfolios } 3 \text { and } 1\end{array}$}} \\
\hline & & Bottom $30 \%$ & Mid $40 \%$ & Top 30\% & & \\
\hline Portfolios & Bottom 30\% & $0.045^{\mathrm{a}}$ & 0.054 & $0.070^{\$ t}$ & 0.024 & {$[0.64]$} \\
\hline \multirow{2}{*}{$\begin{array}{l}\text { of } D A M J_{i, t} \\
\text { (M. Jones) }\end{array}$} & Mid $40 \%$ & $0.036^{\ddagger}$ & $0.029^{*}$ & $0.040^{*}$ & 0.00 & [0.31] \\
\hline & Top $30 \%$ & $0.093^{\text {ta }}$ & -0.023 & $-0.114^{\text {\$tb }}$ & \multicolumn{2}{|c|}{$-0.207 \# \# \#[-3.22]$} \\
\hline \multicolumn{2}{|c|}{$\begin{array}{c}H_{0}: \text { Equal Medians } \\
\text { Portfolios } 3 \text { and } 1\end{array}$} & $\begin{array}{l}0.048 \\
{[0.32]}\end{array}$ & $\begin{array}{c}-0.077 \# \\
{[-1.77]}\end{array}$ & $\begin{array}{c}-0.184 \# \# \# \\
{[-3.59]}\end{array}$ & \multicolumn{2}{|c|}{$\begin{array}{c}H_{0}: \text { Equal Medians } \\
\text { Portfolios b and a } \\
-0.160 \# \# \# \\
{[-2.96]} \\
\end{array}$} \\
\hline \multirow{2}{*}{\multicolumn{2}{|c|}{ 3-month Portfolio BHARs }} & \multicolumn{3}{|c|}{ Portfolios of $\Delta L e v_{i, t}$ (Leverage changes) } & \multirow{2}{*}{\multicolumn{2}{|c|}{$\begin{array}{l}H_{0}: \text { Equal Medians } \\
\text { Portfolios } 3 \text { and } 1\end{array}$}} \\
\hline & & Bottom $30 \%$ & Mid 40\% & Top 30\% & & \\
\hline \multirow{3}{*}{$\begin{array}{l}\text { Portfolios } \\
\text { of } R M_{i, t}\end{array}$} & Bottom $30 \%$ & $0.035^{\hbar, \mathrm{a}}$ & 0.037 & -0.002 & -0.037 & {$[-0.18]$} \\
\hline & Mid $40 \%$ & 0.000 & 0.072 & -0.051 & -0.051 & {$[-0.66]$} \\
\hline & Top $30 \%$ & $0.090^{\dagger+}$ & 0.016 & $0.019^{\mathrm{b}}$ & -0.071 & {$[-0.98]$} \\
\hline \multicolumn{2}{|c|}{$\begin{array}{c}H_{0} \text { : Equal Medians } \\
\text { Portfolios } 3 \text { and } 1\end{array}$} & $\begin{array}{l}0.055 \\
{[0.36]}\end{array}$ & $\begin{array}{l}-0.021 \\
{[-0.21]}\end{array}$ & $\begin{array}{c}0.021 \\
{[-0.49]}\end{array}$ & \multicolumn{2}{|c|}{$\begin{array}{c}H_{0}: \text { Equal Medians } \\
\text { Portfolios b and a } \\
-0.016 \\
{[-0.69]}\end{array}$} \\
\hline
\end{tabular}


Panel B: 12-month Portfolio BHARs

\begin{tabular}{|c|c|c|c|c|c|c|}
\hline \multirow{2}{*}{\multicolumn{2}{|c|}{ 12-month Portfolio BHARs }} & \multicolumn{3}{|c|}{ Portfolios of $\Delta L e v_{i, t}$ (Leverage changes) } & \multirow{2}{*}{\multicolumn{2}{|c|}{$\begin{array}{l}H_{0}: \text { Equal Medians } \\
\text { Portfolios } 3 \text { and } 1\end{array}$}} \\
\hline & & Bottom 30\% & Mid $40 \%$ & Top 30\% & & \\
\hline \multirow{3}{*}{$\begin{array}{l}\text { Portfolios } \\
\text { of } D A M J_{i, t} \\
\text { (M. Jones) }\end{array}$} & Bottom $30 \%$ & $0.096^{\mathrm{a}}$ & -0.058 & 0.001 & -0.095 & {$[-0.71]$} \\
\hline & Mid $40 \%$ & 0.031 & $0.091^{*}$ & -0.037 & -0.068 & {$[-0.84]$} \\
\hline & Top $30 \%$ & 0.087 & 0.046 & $-0.013^{\mathrm{b}}$ & -0.100 & {$[-1.00]$} \\
\hline \multicolumn{2}{|c|}{$\begin{array}{c}H_{0} \text { : Equal Medians } \\
\text { Portfolios } 3 \text { and } 1\end{array}$} & $\begin{array}{l}-0.009 \\
{[-0.67]}\end{array}$ & $\begin{array}{c}0.104 \\
{[0.37]}\end{array}$ & $\begin{array}{l}-0.014 \\
{[-0.90]}\end{array}$ & \multicolumn{2}{|c|}{$\begin{array}{c}H_{0}: \text { Equal Medians } \\
\text { Portfolios b and a } \\
-0.109 \\
{[-1.62]}\end{array}$} \\
\hline \multirow{2}{*}{\multicolumn{2}{|c|}{ 12-month Portfolio BHARs }} & \multicolumn{3}{|c|}{ Portfolios of $\Delta L e v_{i, t}$ (Leverage changes) } & \multirow{2}{*}{\multicolumn{2}{|c|}{$\begin{array}{c}H_{0}: \text { Equal Medians } \\
\text { Portfolios } 3 \text { and } 1\end{array}$}} \\
\hline & & Bottom $30 \%$ & Mid $40 \%$ & Top 30\% & & \\
\hline \multirow{3}{*}{$\begin{array}{l}\text { Portfolios } \\
\text { of } R M_{i, t}\end{array}$} & Bottom $30 \%$ & $0.095^{\ddagger, a}$ & 0.099 & -0.013 & -0.108 & {$[-1.36]$} \\
\hline & Mid $40 \%$ & 0.007 & 0.078 & -0.013 & -0.020 & {$[-1.21]$} \\
\hline & Top $30 \%$ & 0.137 & 0.021 & $0.002^{\mathrm{b}}$ & -0.135 & [-1.23] \\
\hline \multicolumn{2}{|c|}{$\begin{array}{c}H_{0}: \text { Equal Medians } \\
\text { Portfolios } 3 \text { and } 1\end{array}$} & $\begin{array}{l}0.042 \\
{[0.12]}\end{array}$ & $\begin{array}{l}-0.077 \\
{[-1.23]}\end{array}$ & $\begin{array}{l}0.015 \\
{[0.08]}\end{array}$ & \multicolumn{2}{|c|}{$\begin{array}{c}H_{0}: \text { Equal Medians } \\
\text { Portfolios b and a } \\
-0.093 \\
{[-1.36]}\end{array}$} \\
\hline
\end{tabular}

Panel C: 24-month Portfolio BHARs

\begin{tabular}{|c|c|c|c|c|}
\hline \multicolumn{2}{|c|}{ 24-month Portfolio BHARs } & \multicolumn{3}{|c|}{ Portfolios of $\Delta L e v_{i, t}$ (Leverage changes) } \\
\hline & & Bottom $30 \%$ & Mid $40 \%$ & Top $30 \%$ \\
\hline Portfolios & Bottom 30\% & $0.177^{\mathrm{a}}$ & 0.059 & $0.261^{\text {楆 }}$ \\
\hline \multirow{2}{*}{$\begin{array}{l}\text { of } D A M J_{i, t} \\
\text { (M. Jones) }\end{array}$} & Mid $40 \%$ & $0.292^{\text {蝶 }}$ & $0.274^{\mathrm{mt}}$ & 0.012 \\
\hline & Top 30\% & 0.000 & -0.018 & $-0.010^{\mathrm{b}}$ \\
\hline \multicolumn{2}{|c|}{$\begin{array}{l}H_{0} \text { : Equal Medians } \\
\text { Portfolios } 3 \text { and } 1\end{array}$} & $\begin{array}{l}-0.177 \\
{[-0.94]}\end{array}$ & $\begin{array}{l}-0.077 \\
{[-0.85]}\end{array}$ & $\begin{array}{l}-0.271 \\
{[-1.61]}\end{array}$ \\
\hline
\end{tabular}

\begin{tabular}{c}
$\begin{array}{c}H_{0}: \text { Equal Medians } \\
\text { Portfolios }\end{array}$ and 1 \\
\hline $0.084 \quad[0.94]$
\end{tabular}

$-0.208 \# \# \#[-2.59]$

$-0.010 \quad[0.41]$

$H_{0}$ : Equal Medians

Portfolios $b$ and a

$-0.187$

$[-0.66]$

\begin{tabular}{|c|c|c|c|c|}
\hline \multicolumn{2}{|c|}{ 24-month Portfolio BHARs } & \multicolumn{3}{|c|}{ Portfolios of $\Delta L e v_{i, t}$ (Leverage changes) } \\
\hline & & Bottom $30 \%$ & $\operatorname{Mid} 40 \%$ & Top $30 \%$ \\
\hline \multirow{3}{*}{$\begin{array}{c}\text { Portfolios } \\
\text { of } R M_{i, t}\end{array}$} & Bottom $30 \%$ & $0.083^{\mathrm{a}}$ & 0.117 & 0.066 \\
\hline & Mid $40 \%$ & $0.144^{\#}$ & 0.074 & -0.061 \\
\hline & Top 30\% & $0.202^{\sharp+}$ & 0.036 & $-0.070^{\mathrm{b}}$ \\
\hline \multicolumn{2}{|c|}{$\begin{array}{l}H_{0} \text { : Equal Medians } \\
\text { Portfolios } 3 \text { and } 1\end{array}$} & $\begin{array}{l}0.119 \\
{[0.69]}\end{array}$ & $\begin{array}{l}-0.081 \\
{[-0.84]}\end{array}$ & $\begin{array}{l}-0.136 \\
{[-0.47]}\end{array}$ \\
\hline
\end{tabular}

\begin{tabular}{c}
$\begin{array}{c}H_{0}: \text { Equal Medians } \\
\text { Portfolios } 3 \text { and } 1\end{array}$ \\
\hline$-0.016 \quad[-0.69]$
\end{tabular}

$-0.205 \# \# \quad[-2.04]$

$-0.272 \# \quad[-1.80]$

$H_{0}$ : Equal Medians

Portfolios $\mathrm{b}$ and $\mathrm{a}$

$-0.153$

$[-1.22]$ 


\section{Appendix A}

In this Appendix, we report buy-and-hold abnormal return (BHAR) for sample suspect firms with Altman's Z score (Alt $\left.Z_{i, t}\right)$ values $<1.81$ ('Distressed firms') and Z Score values above or equal to 1.81 ('Healthy firms') grouped into one of five leverage $\left(\right.$ Lev $\left._{i, t}\right)$ annually rebalanced portfolios.

Table A1: Suspect Firm Leverage and Market Performance. The Table reports equally-weighted median buy-and-hold abnormal return $(B H A R)$, starting from April of year $t+l$ over the next 3, 12 and 24 months across all sample years, for sample suspect firms with Altman's $Z$ score ( $\left.A l t Z_{i, t}\right)$ values $<1.81$ ('Distressed firms') and Z Score values above or equal to 1.81 ('Healthy firms') grouped into one of five leverage ( $\left.L e v_{i, t}\right)$ annually rebalanced portfolios. A $\dagger$, $\dagger \dagger$, $\dagger \dagger \dagger$ indicates that the portfolio median is statistically different from zero at the $10 \%, 5 \%$ and $1 \%$ significance level respectively. A $\$$, $\$$ and $\$+$ indicates that the Wilcoxon rank sum test statistic rejects the null hypothesis that the BHAR of firms with an Altman's Z score below/above the cut-off level are from distributions with equal medians at the $10 \%, 5 \%$ and $1 \%$ significance level respectively. $\mathrm{z}$-values of the Wilcoxon rank sum test statistic appear in square brackets.

\begin{tabular}{|c|c|c|c|c|c|c|c|c|c|}
\hline \multirow{3}{*}{$\begin{array}{l}\text { Portfolios } \\
\qquad e v_{i, t}\end{array}$} & \multicolumn{3}{|c|}{ 3-month $B H A R$} & \multicolumn{3}{|c|}{ 12-month $B H A R$} & \multicolumn{3}{|c|}{ 24-month $B H A R$} \\
\hline & \multicolumn{2}{|c|}{ Portfolios of Alt $Z_{i, t}$} & \multirow{2}{*}{$\begin{array}{c}\text { Difference } \\
\text { Port. 2-Port. } 1\end{array}$} & \multicolumn{2}{|c|}{ Portfolios of $A l t Z_{i, t}$} & \multirow{2}{*}{$\begin{array}{c}\text { Difference } \\
\text { Port. 2-Port. } 1\end{array}$} & \multicolumn{2}{|c|}{ Portfolios of Alt $Z_{i, t}$} & \multirow{2}{*}{$\begin{array}{c}\text { Difference } \\
\text { Port. 2-Port. } 1\end{array}$} \\
\hline & $\begin{array}{c}1- \\
\text { Distressed }\end{array}$ & $\begin{array}{c}2- \\
\text { Healthy }\end{array}$ & & $\begin{array}{c}1- \\
\text { Distressed }\end{array}$ & $\begin{array}{c}2- \\
\text { Healthy }\end{array}$ & & $\begin{array}{c}1- \\
\text { Distressed }\end{array}$ & $\begin{array}{c}2- \\
\text { Healthy }\end{array}$ & \\
\hline 1-Lowest & -0.0470 & 0.0001 & $0.0471^{\dagger}[1.81]$ & -0.0061 & 0.0028 & $0.0089[0.59]$ & $-0.1784^{\dagger \dagger \dagger}$ & 0.0069 & $0.1853^{\text {tt }}[2.08]$ \\
\hline 2 & -0.0273 & $0.0079^{\dagger \dagger}$ & $0.0352 *[2.04]$ & -0.0181 & $0.0394^{\dagger \dagger \dagger}$ & $0.0575 \quad[1.03]$ & -0.0323 & $0.0333^{\dagger}$ & $0.0656[0.36]$ \\
\hline 3 & -0.0181 & 0.0003 & $0.0184 \quad[0.59]$ & $0.0332^{\dagger \dagger}$ & 0.0001 & $-0.0331^{+1+1}[-2.50]$ & -0.0030 & -0.0004 & $0.0026 \quad[-0.22]$ \\
\hline 4 & -0.0182 & 0.0086 & $0.0269 \quad[1.49]$ & -0.0087 & 0.0037 & $0.0124[-0.78]$ & -0.0490 & 0.0081 & $0.0570 \quad[0.15]$ \\
\hline 5-Highest & $0.0537^{\dagger \dagger \dagger}$ & $0.0188^{\dagger \dagger \dagger}$ & $-0.0349^{*+}[-3.18]$ & $0.0146^{\dagger}$ & $0.0465^{\dagger \dagger}$ & $0.0320[0.69]$ & $0.0274^{\dagger \dagger \dagger}$ & $0.0584^{\dagger \dagger \dagger}$ & $0.0311 \quad[0.12]$ \\
\hline
\end{tabular}

